\title{
A Inserção do Migrante Rural no Mercado de Trabalho Urbano no Brasil: Uma Análise Empírica da Importância dos Setores Informal e Formal *
}

\author{
Hilton Martins de Brito Ramalho \\ Professor - Departamento de Economia (UFPB e do PPGE/UFPB) \\ Endereço para contato: CCSA - Jardim Cidade Universitária - João Pessoa - PB \\ CEP: 58051-900 - E-mail: hiltonmbr@gmail.com

\section{Raul da Mota Silveira Neto} \\ Professor - Departamento de Economia e do PIMES/UFPE e CNPq \\ Endereço para contato: CCSA - Av. dos Economistas, S/N - Cidade Universitária - Recife - PE \\ CEP: 50740-590 - E-mail: rau.silveira@uol.com.br
}

Recebido em 13 de junho de 2011 . Aceito em 11 de setembro de 2012.

\section{Resumo}

Este artigo analisa a inserção do migrante rural-urbano no mercado de trabalho urbano no Brasil. Primeiro, fornece evidências sobre a importância do capital humano para a inserção do migrante brasileiro entre setores formal e informal. Em segundo lugar, investiga se o setor informal funciona como um estágio de transição para os migrantes à procura de um emprego melhor no setor formal e, em terceiro, examina se a alocação do migrante rural-urbano no mercado de trabalho reflete a sua melhor escolha possível, considerando os retornos esperados para as características individuais. Os resultados indicam que a probabilidade de ingresso do migrante no setor formal é diretamente relacionada com a dotação de capital humano, e que há barreiras à entrada em alguns segmentos. As evidências sugerem que boa parte dos migrantes ocupados como assalariados na economia informal procura, após certo tempo de vida nas cidades, um melhor emprego no setor formal.

\section{Palavras-Chave}

migração rural-urbana, capital humano, setor informal, escolha ocupacional

\begin{abstract}
This paper provides an empirical analysis of the insertion of the rural-urban migrant into the urban labor market in Brazil. Three different aspects are specifically considered. First, it provides evidence for the importance of human capital to the insertion of Brazilian rural-urban migrants between formal and informal sector. Second, it investigates if the Brazilian informal sector can be considered as a transitory stage for the migrant who intends to work in the formal sector. Finally, it analyses if the observed insertion of Brazilian rural-urban migrant in the labor market reflects his best possible choice given expected returns to his individual characteristics. The results indicate that the migrant
\end{abstract}

- Os autores agradecem o CNPQ pelo apoio financeiro por meio do Edital CNPq 02/2010 Ciências Humanas, Sociais e Sociais Aplicadas, Processo no 401476/2010-3. 
human capital is positively associated to the chance of being allocated to formal sector and that there are barriers to entry in some sectors. The set of evidence is also consistent with the idea that urban informal sector represent a temporary stage for the migrant who intends to work in the formal sector.

\section{Keywords}

rural-urban migration, human capital, informal sector, occupational choice

\section{JEL Classification}

J24, J31, J61

\section{Introdução}

A elevada concentração da população nas zonas rurais e a presença de relações informais no mercado de trabalho são características importantes na maioria das economias em desenvolvimento. Nesse contexto, a migração do trabalho direcionada das áreas rurais para as urbanas é reconhecida como fator relevante no processo de urbanização, guardando relação histórica com o processo de desenvolvimento em vários países (Lall et al., 2006). Todavia, diversos fatores históricos condicionaram mudanças nas dimensões e estrutura dos mercados de trabalho rural e urbano dos países em desenvolvimento, a exemplo de países continentais e populosos como Brasil, China e Índia.

Ao contrário da China e da Índia, o Brasil registra, atualmente, menos de $20 \%$ de sua população vivendo no meio rural, a exemplo dos Estados Unidos (21\%), e diferentemente da China (64\%) e da Índia (73\%) (United Nations, 2007). Por outro lado, assemelha-se aos últimos países, onde o setor informal responde por uma parcela significante da população urbana ocupada. Conforme dados da Organização para a Cooperação e Desenvolvimento Econômico (OECD), durante a década de 90 as ocupações informais representaram $45 \%$ do total de empregos nas áreas urbanas do Brasil, 52\% na China e 92\% na Índia (OECD, 2007).

Embora o Brasil represente um caso interessante, com parcela relativamente pequena da população no meio rural e um peso relativamente elevado do emprego no setor informal urbano, não são abundantes as evidências disponíveis na literatura econômica sobre a questão específica da inserção do migrante da rota rural-urbana 
no mercado de trabalho urbano, particularmente no setor informal. Entre estes poucos trabalhos da literatura econômica que tratam especificamente da questão, Yap (1976) analisou a inserção dos emigrantes rurais nas cidades brasileiras, a partir dos dados do Censo Demográfico de 1960. Seus resultados indicaram que os migrantes da rota rural-urbana têm maior probabilidade de emprego no setor informal, porém, tais achados são estatisticamente pouco críveis, além de não fornecerem estimativas atualizadas.

Na literatura internacional, Cole e Sanders (1985) estabeleceram uma importante conexão teórica entre o processo de urbanização e a estrutura do mercado de trabalho. Os autores argumentam que os trabalhadores rurais dotados de baixa instrução se dirigem para as cidades à procura de um emprego temporário no setor informal, e após algum tempo de vida na cidade, tentam encontrar uma melhor ocupação no setor formal. Assim, as diferenças de capital humano podem determinar a alocação dos migrantes no mercado de trabalho urbano, e a migração rural-urbana ocorreria mesmo sem perspectivas iniciais de emprego no setor formal.

Nesse contexto, Banerjee (1983), em estudo pioneiro para Índia, constatou que o nível de educação é decisivo para aumentar a probabilidade de emprego do migrante rural-urbano no setor formal. Já Meng (2001), ao estudar a migração rural-urbana na China, mostrou que o setor informal permite oportunidades de emprego e de bem-estar diferenciadas pelo tipo de ocupação exercida. Os trabalhadores assalariados tendem a permanecer temporariamente na informalidade, enquanto aqueles empregados por conta própria teriam oportunidades mais estáveis, as quais exigiriam habilidades mais específicas.

Durante a década de 90, a economia brasileira registrou um significante aumento nos empregos informais, os quais chegaram a responder por quase 50\% das ocupações no final dos anos 2000 (OECD, 2007). Nesse período, a migração rural-urbana atuou como importante mecanismo de realocação das pessoas no país. Portanto, este trabalho pretende investigar o papel do setor informal no processo de migração rural-urbana no Brasil, preenchendo uma lacuna relevante na literatura nacional. Em particular, as seguintes questões são investigadas: (i) qual a importância das dotações individuais de capital humano na inserção do migrante entre os setores formal e informal do 
mercado de trabalho? (ii) o setor informal funciona como um estágio transitório para o migrante que busca um melhor emprego no setor formal? e (iii) dados os atributos pessoais, a alocação observada do migrante rural-urbano no mercado de trabalho representa a melhor escolha segundo os retornos salariais esperados?

O interesse específico na rota rural-urbana decorre do fato de que, com mais baixa escolaridade e sem habilidades específicas para parte importante das ocupações do setor urbano, o migrante da referida rota apresenta maiores chances de fazer uso do mercado de trabalho urbano informal como estágio para uma futura inserção no mercado formal de trabalho do meio urbano (Banerjee, 1983; Meng 2000). Logo, o presente estudo representa, pois, uma oportunidade para melhor apreensão da importância dos segmentos informais e formais como destino dos migrantes. Além disto, considerando as disparidades regionais brasileiras e ainda grande participação do meio rural na região Nordeste, onde cerca de 29,8\% das ocupações em 2009 ainda estavam vinculadas a atividades deste meio (IBGE, 2009), espera-se que tal particular rota ainda represente por algum tempo um trajeto importante para os habitantes das áreas mais pobres do país.

O artigo está organizado como segue. A segunda seção faz uma breve revisão da literatura nacional sobre setor informal urbano e migração rural-urbana. A terceira seção apresenta a estratégia empírica adotada. A quarta seção descreve base de dados, seleção e tratamento de variáveis, assim como as características socioeconômicas dos migrantes. Na quinta e sexta seções são apresentados e discutidos os resultados empíricos referentes à alocação do migrante rural-urbano no mercado de trabalho e retornos salariais. Por fim, a última seção é reservada à conclusão.

\section{Setor Informal Urbano e Migração Rural-Urbana no Brasil}

No final dos anos 2000, o emprego informal representava aproximadamente $45 \%$ do total dos ocupados no mercado de trabalho brasileiro (OECD, 2007), um percentual bem acima daquele que vigorava no início dos anos 1990, que não chegava a 30\% (Ulyssea, 2006). $\mathrm{Na}$ verdade, tal elevação da importância das ocupações informais nas últimas décadas reflete tanto o crescimento do setor de serviços, como 
a elevação da informalidade no próprio setor industrial, movimentos ocorridos nos anos 1990 (Ramos, 2002; Ulyssea, 2006).

Bem documentadas em diferentes estudos, as características produtivas do trabalhador do setor informal brasileiro, em geral, indicam menor produtividade deste quando cotejado com o trabalhador do setor formal. Embora entre 1990 e 2000 a média de anos de estudos dos trabalhadores do setor informal tenha se elevado mais rapidamente que a média geral de anos de estudos dos trabalhadores brasileiros (Curi e Menezes-Filho, 2004), o trabalhador do setor informal ainda se apresenta com menor escolaridade (anos de estudos) que o trabalhador do setor formal (Cacciamali e Fernandes, 1993; Soares, 2004), um resultado consistente com a menor remuneração média observada para o primeiro. Da mesma forma, há consenso na literatura brasileira de que o emprego informal associado ao trabalho assalariado caracteriza-se por maior rotatividade, menor duração e está positivamente associado às condições de pobreza (Ulyssea, 2006).

Tais evidências não indicam, necessariamente, a existência de um mercado de trabalho segmentado no Brasil, ou seja, trabalhadores com mesma habilidade sendo alocados em setores com remunerações diferentes devido à escassez de ocupações no segmento formal e/ou barreiras à entrada. A este respeito, as evidências disponíveis para o mercado de trabalho brasileiro são controversas. Tannuri-Pianto e Pianto (2002), por exemplo, defendem que a hipótese de segmentação se faz presente para os trabalhadores de menores níveis de renda. Por outro lado, Neri (2002) e Curi e Menezes-Filho (2004), ao apresentarem evidências sobre taxas de transição entre as ocupações, sugerem a inexistência de segmentação no mercado de trabalho brasileiro. ${ }^{1}$

No que diz respeito à experiência de mercado de trabalho do migrante de origem rural, há, no caso brasileiro, muito pouca evidência disponível. Nenhum dos artigos citados acima trata especificamente da questão da inserção do migrante oriundo do meio rural no mercado de trabalho. Na verdade, o estudo feito por Yap (1976) é a única referência na literatura econômica que aborda especificamente a referida questão. A partir dos microdados do Censo Demográfico de 1960, a autora apresenta evidências de que o migrante brasileiro da rota rural-urbana possui mais chances de inserção no segmento

1 Ver Ulyssea (2006) para uma maior discussão destes pontos. 
informal que formal. A despeito da relevância e pioneirismo do trabalho, a autora não considera as diferentes ocupações presentes no setor informal (assalariado e emprego como autônomo), o possível viés de seleção na escolha das ocupações e, muito menos, o provável caráter funcional do mercado informal como estágio transitório para os segmentos formais, pontos tratados neste trabalho.

\section{Estratégia Empírica}

Esta seção é reservada à estratégia empírica do presente trabalho e encontra-se dividida em três partes. Na primeira, apresenta-se um modelo estrutural de determinação conjunta da escolha ocupacional e rendimentos dos migrantes de rota rural-urbana. A segunda parte aborda o método de Lee (1983) para correção de viés de seleção amostral atrelado às habilidades não observadas dos migrantes entre distintas categorias de ocupação nos setores formal e informal.

Por fim, na terceira parte são discutidas algumas técnicas para exercícios contrafactuais (Tunali, 2000; Meng, 2001; Piracha e Vadean, 2009), as quais serão usadas para avaliar a relação entre o tempo de residência do migrante na cidade e a sua transição no mercado de trabalho e, em uma etapa seguinte, a consistência entre a escolha ocupacional observada e a diferença entre o rendimento auferido na ocupação real e aquele resultante de uma potencial mudança de emprego.

\subsection{Modelo de Determinação Conjunta de Ocupação e Salários}

A importância das diferenças de capital humano e/ou a presença de barreiras à entrada em determinados setores do mercado de trabalho podem desempenhar um papel relevante na alocação inicial dos migrantes nas cidades. Nesse sentido, o presente modelo considera categorias ocupacionais capazes de permitir uma melhor distinção dos trabalhadores migrantes quanto às habilidades observadas e não observadas. Para tanto, sejam as seguintes escolhas ou possibilidades factíveis: 1 - trabalhar como assalariado ou autônomo no setor formal privado; 2 - trabalhar como assalariado no setor informal; 
3 - trabalhar como autônomo no setor informal e 4 - trabalhar no setor público. ${ }^{2}$

O benefício líquido obtido a partir da ocupação é dado por uma função de utilidade estocástica:

$$
U_{j}=\gamma_{j} \ln W_{j}+Z_{j} \theta_{j}+v_{j}
$$

Onde: $j$, doravante, indexa as quatro categorias de ocupação supracitadas $(j=1,2,3,4) ; \operatorname{In} W_{j}$ é o logaritmo da renda do trabalho no setor $j ; Z j$ é um vetor de atributos pessoais relacionados aos custos de procura por trabalho; $\gamma_{j}$ e $\theta_{j}$ (vetor) são parâmetros estruturais e $v_{j}$ é o termo de erro randômico.

Cada escolha ocupacional está relacionada a um valor de remuneração que, por seu turno, depende de um vetor de atributos observados $X_{j} \mathrm{e}$ de outro vetor aleatório $u_{j}$ normalmente distribuído e com variância constante, que representa características não observáveis. ${ }^{3}$ Portanto, para cada categoria de ocupação, tem-se uma equação de salários do tipo minceriana:

$$
\ln W_{j}=X_{j} \beta_{j}+u_{j}
$$

Onde: $\beta_{j}$ é um vetor de parâmetros (incluindo intercepto).

A versão reduzida do modelo estrutural (equação de seleção ocupacional) pode ser obtida substituindo (2) em (1) e redefinindo os termos:

$$
\begin{gathered}
U_{j}^{*}=\gamma_{j}\left(X_{j} \beta_{j}+u_{j}\right)+Z_{j} \theta_{j}+v_{j}=\left(\gamma_{j} X_{j} \beta_{j}+Z_{j} \theta_{j}\right)+ \\
\left(\gamma_{j} u_{j}+v_{j}\right)=V_{j}+\epsilon_{j}
\end{gathered}
$$

Onde: $U_{j}^{*}$ é uma variável latente não observada que mensura o benefício associado à escolha ocupacional; $V_{j} \equiv\left(\gamma_{j} X_{j} \beta_{j}+Z_{j} \theta_{j}\right)$ e $\epsilon_{j} \equiv\left(\gamma_{j} u_{j}+v_{j}\right)$ representam, respectivamente, combinações de atri-

\footnotetext{
Na seção 4, justifica-se mais precisamente o uso dessas quatro categorias.

3 Embora a estratégia do presente estudo não seja centrada na estimativa da Equação (1), vale ressaltar que a identificação dos seus parâmetros estruturais requer a imposição de restrições por exclusão, ou seja, que alguns atributos observados presentes no vetor $Z_{j}$ sejam excluídos do vetor $X_{j}$, dado que os primeiros devem se relacionar apenas com os custos de procura por trabalho. A seleção dos componentes do vetor pode levar em conta sugestões teóricas e/ou ausência de correlação estatística com os rendimentos (Puhani, 2000; Loskin e Sajaia, 2004).
} 
butos observados e não observados que explicam a determinação da categoria de ocupação e dos rendimentos.

A ocupação escolhida pelo migrante dependerá do beneficio líquido máximo, ou seja, o trabalhador optará pela alternativa $k$ se, e somente se, esta escolha proporcionar o maior ganho de utilidade em relação ao conjunto $\Omega=\{1,2,3,4\}$ de alternativas viáveis. Formalmente, a seguinte condição deveria ser satisfeita $U_{k}^{*}=V_{k}+\epsilon_{k} \geq \operatorname{Max}_{j \in \Omega}\left\{U_{j}^{*}\right\}=V_{\Omega}+\epsilon_{\Omega} \forall k \neq j$, ou o equivalente a $\eta_{k} \equiv \epsilon_{\Omega}-\epsilon_{k} \leq V_{k}-V_{\Omega} \equiv A_{k}$, onde $A_{k}$ e $\eta_{k}$ representam, respectivamente, diferenças de utilidade por escolha ocupacional em termos de fatores observados e não observados.

Ao se admitir que o termo $\epsilon_{j}$ segue uma distribuição de Gumbel, então $V_{\Omega}=\ln \left[\sum \exp \left(V_{j}\right)\right]$ e $\eta_{k}$ seguirá uma distribuição logística (Vijverberg, 1995). Tais pressupostos permitem que a probabilidade condicionada de ocupação do migrante na categoria seja estimada por Máxima Verossimilhança a partir de um logit multinominal $p_{k}=\operatorname{prob}\left(\eta_{k} \leq A_{k}\right)=F\left(A_{k}\right)=\frac{1}{1+\exp \left(A_{k}\right)}$, onde $F$ é uma função de densidade logística acumulada ${ }^{4}$ (Maddala, 1983).

Vale destacar que os termos randômicos de (2) e (3) são correlacionados, ${ }^{5}$ uma vez que o modelo admite uma interdependência entre a escolha ocupacional do migrante e o rendimento esperado. Em outras palavras, os atributos produtivos não observados que influenciam a inserção na ocupação também afetam o rendimento auferido. Portanto, a estimativa isolada da Equação de salários (2) pode gerar coeficientes tendenciosos em razão da autosseleção dos migrantes (Vijverberg, 1995; Dahl, 2002).

Com o intuito de superar o referido problema, Lee (1983) fez uma extensão do método tradicional de correção para viés de seleção amostral proposto por Heckman (1979), considerando o caso em que a seletividade envolve múltiplas escolhas. A seguir, faz-se uma breve descrição da referida estratégia, adotada na presente investigação.

${ }^{4}$ No modelo logit multinomial, os parâmetros só podem ser estimados a partir da escolha de uma categoria de referência (Greene, 2002).

5 Conforme pode ser observado na Equação (3), $\epsilon_{j}$ é ao menos uma combinação linear de $u_{j}$. 


\subsection{A Correção para Viés de Seleção Amostral no Contexto de Múlti- plas Escolhas}

Dado que termos aleatórios $u_{j}$ e $\epsilon_{j}$ são supostamente correlacionados e seguem distintas distribuições de probabilidades, respectivamente, distribuições Normal e de Gumbel, Lee (1983) demonstrou que é possível modificar a variável randômica $\eta_{k}$ de modo que a mesma seja normalmente distribuída. Para tanto, considerou a seguinte transformação $\eta_{k}^{n} \equiv \Phi^{-1}\left[F\left(\eta_{k}\right)\right]$, em que $\Phi^{-1}$ é a inversa da função de densidade normal acumulada. Conforme já discutido, a escolha ocupacional $k$ apenas será racional se $\eta_{k} \leq A_{k}$, de modo que a transformação anterior implica $\eta_{k}^{n} \leq \Phi^{-1}\left[p_{k}\right]=A_{k}^{n}$. Em consonância com o método tradicional de Heckman (1979), Lee (1983) supõe que as variáveis aleatórias $u_{j}$ e $\eta_{k}^{n}$ seguem uma distribuição normal conjunta com covariância $\sigma_{u \eta}$, o que permite obter o valor esperado do rendimento derivado da ocupação $k$ :

$$
E\left(\ln W_{k} \mid \eta_{k} \leq A_{k}\right)=X_{k} \hat{\beta}_{k}+\hat{\sigma}_{u \eta} \lambda_{k}
$$

Onde: $\lambda_{k} \equiv \frac{\phi\left[\Phi^{-1}\left[\hat{p}_{k}\right]\right]}{\hat{p}_{k}}$ é a variável de correção do viés de seleção amostral ${ }^{6}$ associado ao migrante alocado na categoria de ocupação $k$;

$\phi$ é a função de densidade normal; $\hat{p}_{k}$ é a probabilidade estimada de emprego no setor $k$; $\hat{\beta}_{k}$ um vetor de coeficientes não tendenciosos e $\hat{\sigma}_{u \eta}$ a estimativa da covariância entre $u_{j}$ e $\eta_{k}^{n}$.

Portanto, a partir dos resultados reportados, pode-se resumir o método de Lee (1983) em duas etapas. De início, (a) estimam-se os parâmetros da Equação de seleção (3) através de um logit multinomial e, a partir destas estimativas, prediz-se a probabilidade de o trabalhador migrante ocupar-se na categoria $k$, o que permite obter a variável de correção $\lambda_{k}$ correspondente. Em seguida, (b) a Equação (2) é regredida por Mínimos Quadrados Ordinários (MQO) em uma amostra composta pelos trabalhadores que escolheram a ocupação $k$, incluindo-se $\lambda_{k}$ como covariada adicional (vide Equação (4)). ${ }^{7}$

\footnotetext{
${ }^{6}$ Pode ser considerada uma extensão da taxa inversa de Mills no método de Heckman (1979), isto é, $E\left(u_{k} \mid \eta_{k}^{n} \leq A_{k}^{n}\right)=\hat{\sigma}_{u \eta} \lambda_{k}$.

7 Nelson (1984) mostra que parâmetros estimados por MQO podem não ser eficientes após a introdução da variável de correção para viés de seleção $\lambda_{k}$. Para contornar o referido problema, Cameron e Trivedi (2005) sugerem que os desvios padrão dos referidos coeficientes sejam estimados por técnicas de reamostragem, como o bootstrap.
} 


\subsection{Transição Setorial e Rendimentos: Exercícios Contrafactuais}

Conforme reportado na introdução, este estudo tem interesse em verificar se o setor informal urbano funciona como meio de transição para parte dos emigrantes rurais, sobretudo aqueles com baixa instrução. A estimativa da Equação de seleção (3) por um logit multinomial permite obter as probabilidades condicionadas de ocupação do migrante e, por conseguinte, fazer exercícios contrafactuais. Desse modo, é possível estimar o efeito da experiência de migração sobre as probabilidades de ocupação após a considerar também a influência de todas as variáveis explicativas do modelo de seleção (Piracha e Vadean, 2009).

Neste sentido e mais especificamente, considere-se a diferença entre a probabilidade de escolha da ocupação $j$ caso o migrante recém -chegado (até 1 ano na cidade) tivesse permanecido de 3 a 4 anos no meio urbano (contrafactual) e a probabilidade de escolher a mesma ocupação dado o tempo efetivo na cidade (até 1 ano - factual). Formalmente:

$$
\Delta p_{j}=\frac{e^{\pi_{j}^{S} A^{r}}}{\sum_{k=1}^{4} e^{\pi_{k}^{S} A^{r}}}-\frac{e^{\pi_{j}^{r} A^{r}}}{\sum_{k=1}^{4} e^{\pi_{k}^{r} A^{r}}}
$$

Onde: o primeiro termo da Equação (5) fornece a probabilidade contrafactual e o segundo a probabilidade factual; $k$ indexa as quatro categorias de ocupação: 1 - assalariado/autônomo formal, 2 - assalariado informal, 3 - autônomo informal e 4 - funcionário público.

De acordo com a Equação (5), a probabilidade contrafactual é calculada imputando o vetor de coeficientes $\pi^{S}$ obtido com a estimação do modelo de seleção ocupacional para uma amostra de migrantes que registram de 3 a 4 anos de moradia no meio urbano sobre as características observadas dos migrantes recém-chegados $A^{r}$, isto é, com no máximo 1 ano de residência. Desse modo, uma diferença positiva (negativa) de probabilidade sugere que a vivência do trabalhador migrante no meio urbano favorece (desfavorece) o emprego na ocupação j. Ou seja, a Equação (5) procura mensurar o efeito imputado aos atributos não observados e relacionados ao tempo de residência no meio urbano, como, por exemplo, a absorção de capital humano específico e/ou o contato com redes sociais. 
Outra questão relevante de investigação refere-se à diferença de rendimentos entre migrantes ocupados em distintas categorias de ocupação formal e informal. A decomposição de Blinder-Oaxaca permite avaliar a importância dos atributos produtivos observados e não observados na explicação da diferença de rendimentos entre categorias de ocupação. ${ }^{8}$ Para tanto, considere a equação a seguir, que mede a diferença média de salário-hora entre migrantes ocupados na categoria $j$ e na categoria $k$ :

$$
\Delta W_{j} \equiv \ln W_{j}-\ln W_{k}=\bar{X}_{k}\left(\hat{\beta}_{j}-\hat{\beta}_{k}\right)+\hat{\beta}_{j}\left(\bar{X}_{j}-\bar{X}_{k}\right)
$$

Onde: $\bar{X}_{j}$ e $\bar{X}_{k}$ são vetores que contém valores médios dos atributos determinantes dos rendimentos, respectivamente, para trabalhadores ocupados nas categorias $j$ e $k ; \hat{\beta}_{j}$ e $\hat{\beta}_{k}$ são vetores de parâmetros corrigidos para viés de seleção amostral, obtidos com estimativas da Equação (4) para migrantes nas ocupações $j$ e $k$.

O termo $\bar{X}_{k}\left(\hat{\beta}_{j}-\hat{\beta}_{k}\right)$ mensura a diferença de salários explicada por atributos produtivos não observados (discriminação), isto é, a diferença média de salário que o migrante ocupado na categoria $k$ obteria caso estivesse empregado (valorado) na categoria $j$. Já o componente $\hat{\beta}_{j}\left(\bar{X}_{j}-\bar{X}_{k}\right)$ calcula o hiato de rendimentos devido às diferenças de atributos produtivos observados (diferença justificada), ou seja, caso migrantes com diferentes características médias fossem valorados na mesma categoria de ocupação. Portanto, os referidos termos permitem inferir acerca das proporções de diferença salarial entre categorias ocupacionais imputadas a atributos produtivos observados e não observados. ${ }^{9}$

Todavia, apesar de a decomposição de Blinder-Oaxaca fornecer indícios relevantes para a análise da autosseleção dos trabalhadores migrantes entre as categorias de ocupação, não permite uma avaliação da distribuição das diferenças de salários e de sua relação com a escolha ocupacional. Para superar a referida limitação, incorpora-se na estratégia empírica desse estudo técnicas não paramétricas para estimativa da distribuição dos hiatos de rendimentos (funções de densidade - histograma), conforme descrito a seguir.

\footnotetext{
8 Vide Oaxaca e Ransom (1999).

9 Uma vez que a decomposição é feita para diferenças de salários potenciais (não condicionados), o termo de correção para seletividade em (4) não é considerado. Por outro lado, também cabe frisar que os desvios padrão dos componentes da equação de decomposição podem ser calculados de forma robusta. Para uma visão geral dos referidos pontos, vide Jann (2008).
} 
As estimativas da Equação de rendimentos (4) para amostras separadas de trabalhadores por categoria ocupacional permitem fazer predições lineares dentro e fora de cada amostra, ou seja, comportam predições de rendimentos factuais e contrafactuais. Para exemplificar, considere-se a diferença entre o salário-hora factual (rendimento da ocupação escolhida) e contrafactual (remuneração obtida caso o migrante houvesse optado por outra ocupação), doravante chamado de retorno econômico à escolha ocupacional: ${ }^{10}$

$$
\begin{gathered}
R_{j} \equiv E\left(\ln W_{j} \mid \Omega=j\right)-E\left(\ln W_{k} \mid \Omega=k\right)=R_{j}^{p}+R_{j}^{S} \\
=X_{j}\left(\hat{\beta}_{j}-\hat{\beta}_{k}\right)+\left(\hat{\sigma}_{u \eta}^{j}-\hat{\sigma}_{u \eta}^{k}\right) \lambda_{j}
\end{gathered}
$$

Onde: o termo $R_{j}^{p} \equiv X_{j}\left(\hat{\beta}_{j}-\hat{\beta}_{k}\right)$ é o retorno econômico potencial (baseado na distribuição marginal dos rendimentos - independe da condição de ocupação), ${ }^{11}$ isto é, a diferença entre o salário-hora (em log.) predito para os trabalhadores ocupados na categoria $j$ (factual) e o salário-hora desses mesmos trabalhadores caso estivessem empregados na categoria $k$ (contrafactual); $R_{j}^{s} \equiv\left(\hat{\sigma}_{j}-\hat{\sigma}_{k}\right) \lambda_{j}$ mensura o ganho imputado à seletividade em atributos não observados (sorting gains), dada à escolha ocupacional (Tunali, 2000).

A partir do cálculo dos salários factuais, contrafactuais e do retorno econômico potencial para cada trabalhador migrante, é possível utilizar métodos não paramétricos para estimar as distribuições de probabilidade para as referidas variáveis de interesse. No presente estudo, optou-se pelo emprego do estimador de núcleo (kernel) e do histograma, descritos a seguir.

O histograma $\hat{f}_{h}$ é um estimador de distribuição de probabilidade (função de densidade) bastante utilizado em estatística descritiva (Cameron e Trivedi, 2005). A técnica consiste em dividir a variável aleatória $x$ em $h$ intervalos com a mesma largura ao longo da amostra. Assim, cada observação é agrupada em sua respectiva classe, o que

${ }^{10}$ Uma vez que os salários-hora são preditos em logaritmo, o retorno econômico é aproximadamente uma taxa de retorno. Assim, um valor positivo indica ganho econômico para o migrante em caso de mudança de ocupação, e negativo o contrário.

${ }^{11}$ É importante distinguir os conceitos de retorno econômico condicionado (Equação (7)) e retorno econômico potencial. Enquanto o primeiro se baseia em predições com a distribuição condicionada dos rendimentos, o segundo usa predições lineares que consideram a distribuição marginal. Maddala (1983, p.287) ressalta que predições não condicionadas podem ser úteis para avaliar a decisão potencial, enquanto predições condicionadas são mais aplicadas para inferir acerca do fenômeno realizado. 
permite calcular a razão entre a proporção de observações contidas em cada intervalo e a largura do mesmo. Por seu turno, as grandezas calculadas para cada classe são então dispostas em um gráfico que exibe a forma da distribuição de frequências. A equação abaixo resume o procedimento reportado:

$$
\hat{f}_{h}\left(x_{0}\right)=\frac{1}{n h} \sum_{i=1}^{n} \frac{1}{2} I\left(\left|\frac{x_{i}-x_{0}}{h}\right|<1\right)
$$

Onde: $n$ é o tamanho da amostra; $x_{0}$ é o ponto central do intervalo ao qual pertence a i-ésima observação e $I$ é uma função delimitadora do intervalo. ${ }^{12}$ Em razão do interesse particular desse estudo na avaliação da racionalidade econômica envolvida na alocação ocupacional dos migrantes, o histograma será empregado na estimativa da distribuição percentual do retorno econômico potencial, fornecendo um diagnóstico sintético da proporção de migrantes com retornos positivos e/ou negativos.

Por outro lado, o estimador de densidade kernel é uma extensão do histograma e será empregado neste estudo para avaliar o formato e diferença das distribuições de probabilidade dos salários factuais e contrafactuais. Conforme reportado por Cameron e Trivedi (2005), o estimador kernel é dado por:

$$
\hat{f}\left(x_{0}\right)=\frac{1}{n h} \sum_{i=1}^{n} K\left(\frac{x_{i}-x_{0}}{h}\right)
$$

Onde: $h$ agora é interpretado como um parâmetro de suavização (janela) e $K$ (.) é uma função de núcleo, sendo os núcleos gaussiano e Epanechnikov os mais empregados. ${ }^{13}$

Cabe ressaltar que tanto a escolha da janela $h$ como a do núcleo $K($. ) são feitas de forma $a d$ hoc. Entretanto, a escolha do parâmetro de suavização $h$ tem importância decisiva para o viés do estimador

\footnotetext{
${ }^{12} I(A)=1$ se o evento A ocorre, caso contrário $I(A)=0$. Cabe ainda ressaltar que o formato do histograma dependerá do número de intervalos escolhidos para a estimação. A regra de bolso $\operatorname{Min}\left\{\sqrt{n}, \frac{10 \ln (n)}{\ln (10)}\right\}$, por exemplo, é aplicada pelo software Stata para a escolha do número de intervalos (bins).

${ }^{13}$ Para uma visão geral sobre as característica e propriedades das funções de núcleo, vide Cameron e Trivedi (2005, p. 299-300).
} 
(diferença entre a verdadeira distribuição e a estimada). Conforme bem documentado na literatura, há um dilema entre o viés e a variância do estimador (9), de modo que maiores valores para $h$ implicam menor viés e maior variância, e vice-versa. Na prática, o valor de $h$ pode ser obtido pelos métodos plug-in presentes em vários pacotes estatísticos, os quais envolvem a minimização da função de erro quadrado médio (Cameron e Trivedi, 2005). ${ }^{14}$

\section{Base de Dados, Tratamentos e Características dos Migrantes Rural-Urbano}

Os dados utilizados na análise empírica são oriundos dos microdados da amostra do Censo Demográfico de 2000, fornecidos pelo Instituto Brasileiro de Geografia e Estatística (IBGE). A referida base de dados é a mais recente que permite identificar diretamente o migrante intermunicipal de rota rural-urbana no Brasil, isto é, o indivíduo que se encontrava morando no meio urbano na data da entrevista e que, há cinco anos (1995), afirmou residir na zona rural de outro município. Destarte, a classificação do migrante rural-urbano segue o cruzamento das informações sobre o município de residência e setor de residência.

Dada a identificação de 84.237 migrantes rural-urbano, a amostra foi selecionada de modo a caracterizar pessoas que migraram por motivações econômicas, sobretudo, em busca de emprego (Fiess e Verner, 2003). Para tanto, foram considerados apenas indivíduos que, na data de migração, tinham entre 20 e 70 anos $^{15}$ e que estavam ocupados na semana de referência do Censo, exceto empregadores, migrantes com múltiplos empregos e/ou que frequentavam a escola.

Também foram excluídos: (i) trabalhadores com rendimento nulo no trabalho principal e/ou que não informaram o número de horas semanais trabalhadas; ${ }^{16}$ (ii) migrantes que não souberam informar a raça e/ou a região que moravam em 1995. Após os referidos filtros,

${ }^{14}$ Um plug-in bastante usando é o de Silverman (1986), o qual baseado na hipótese de distribuição normal sugere que o valor da janela deve ser dado por $h^{*}=1,3643 n^{-0,2} \min \left(s, \frac{i q r}{1,349}\right)$, onde $s$ é o desvio-padrão amostral da variável analisada e iqr são intervalos amostras por quartis (Cameron e Trivedi, 2005, p.304).

${ }^{15}$ Para o cálculo da idade na data de migração, foi descontado da idade declarada na data de entrevista o tempo de residência do migrante no município (em anos).

${ }^{16}$ Esse recorte é comum na literatura e deve-se à restrição imposta pela variável dependente em equações de salários mincerianas (Santos Júnior et al., 2005). 
obteve-se uma amostra de 24.489 migrantes intermunicipais de rota rural-urbana.

A partir do cruzamento de informações sobre a ocupação dos trabalhadores e da condição de contribuição para a previdência social, foi possível agrupar os migrantes em quatro categorias ocupacionais com distintas características formais e informais no mercado de trabalho urbano, a saber: (a) trabalhador formal privado - aquele empregado com carteira assinada ou por conta própria ou sem carteira assinada que contribuía para a previdência social; (b) trabalhador informal assalariado - refere-se ao empregado assalariado sem carteira assinada que não contribuía para a previdência; (c) trabalhador autônomo informal - aquele migrante que se achava ocupado por conta própria e que não registrava contribuição para a previdência e (d) funcionário público - pessoa empregada na administração estatal, isto é, servidores públicos ou militares.

Vale ressaltar que a classificação supracitada é consoante com os objetivos deste trabalho, e segue aquelas empregadas em estudos especializados no âmbito internacional, em que se procura estabelecer uma razoável distinção entre os migrantes segundo atributos produtivos observados e não observados relacionados à ocupação (Banerjee, 1983; Meng, 2001).

Em particular, assume-se que a não contribuição previdenciária é uma característica peculiar do trabalho informal (Saboia e Saboia, 2004) e que o trabalhador informal autônomo tem habilidades específicas que diferem daquelas inerentes aos ocupados como assalariados informais. ${ }^{17}$ Destarte, pode haver uma autosseleção dos migrantes trabalhadores dentro do próprio setor informal do mercado de trabalho. Por outro lado, a distinção entre ocupações formais também se torna pertinente, uma vez que o ingresso no serviço público permite estabilidade no emprego, característica que pode exigir qualificação bastante diferenciada.

Em relação aos condicionantes dos custos de procura por emprego, foram selecionados atributos individuais referentes à estrutura do domicílio, a saber, condição no domicílio (chefia), presença de cônjuge, número de trabalhadores, número de migrantes interestaduais

${ }^{17}$ Um elevado nível de instrução, por exemplo, parece não ser determinante para o ingresso no trabalho autônomo. 
com mais de cinco anos de residência ${ }^{18}$ e número de moradores. Ressalta-se que tais variáveis não entraram nas Equações de salários por categoria ocupacional (4). Por seu turno, outros atributos referentes ao gênero, raça, idade, faixas de escolaridade, região de residência na data do Censo e há cinco anos foram imputados como variáveis explicativas tanto na Equação de seleção (3) como nas equações de rendimentos (vide Equação (4)). No Quadro Al, em apêndice, encontram-se as definições das variáveis reportadas e doravante presentes nas estimações. Vale ressaltar que a consideração das mesmas é consoante com a maioria dos estudos que abordaram a questão da migração e oferta de trabalho (Banerjee; Dolton et al, 1989; Riahd e Rassen, 1998; Meng, 2001; Agesa, 2001, Dimova et al., 2008).

Na Tabela 1, abaixo, são apresentadas características dos migrantes brasileiros de rota rural-urbana segundo as categorias ocupacionais selecionadas, assim como a distribuição dos migrantes entre as mesmas.

É possível observar que, do total de migrantes ocupados em 2000, cerca de $48 \%$ se encontrava no setor formal. Nota-se, além disso, a importância do setor informal como segmento absorvedor de migrantes do meio rural, o qual foi destino de quase $50 \%$ dos referidos trabalhadores. As dificuldades de inserção no setor público, ou mesmo a não preferência com respeito à inserção neste segmento, é ainda mais clara, uma vez que, apenas 1,9\% dos migrantes ingressaram em tal setor.

Embora os homens sejam sempre maioria entre os migrantes na rota rural-urbana, independentemente da alocação, tal maioria é mais significativa entre as pessoas ocupadas nos segmentos formal privado e informal autônomo onde representavam, respectivamente, cerca de $82 \%$ e $75 \%$ das ocupações destes setores. Há, também, interessantes distinções com respeito à cor: indivíduos não brancos são sempre maioria nos segmentos informais e minoria entre os assalariados/ autônomos formais.

\footnotetext{
${ }^{18}$ Esse controle de tempo de residência é importante para evitar interdependência contemporânea (endogeneidade) entre as decisões de migração. Todavia, vale ressaltar que os questionários do Censo Demográfico de 2000 não permitem identificar o migrante intermunicipal por residência anterior, isto é, aquele indivíduo que na data da pesquisa registrava até 9 anos de residência no município e que afirmou já ter residido em outro município durante esse período. Essa caracterização apenas é possível quando se considera a residência anterior em outro estado.
} 
Com respeito às variáveis associadas ao capital humano, nota-se, de início, que os indivíduos ocupados no segmento informal, como autônomos, apresentam a maior média de idade (cerca de 36 anos, quatro anos a mais que a média geral). Tal evidência sugere a exigência de qualificações associadas à experiência e/ou certa acumulação inicial de recursos para ingresso nesta ocupação. Por sua vez, no que diz respeito aos níveis de escolaridade, há um padrão razoavelmente bem definido: os migrantes ocupados nos segmentos formais apresentam níveis de escolaridade mais elevados que aqueles alocados no mercado informal. Por exemplo, enquanto para o segmento formal privado $16 \%$ dos migrantes apresentam 11 ou mais anos de estudos, tal percentual é de apenas 7\% e 9\%, respectivamente, para os assalariados informais e autônomos informais. Tais diferenças são ainda maiores se a referência da formalidade nas relações de trabalho é a ocupação no setor público, no qual 40\% dos migrantes ocupados nesse segmento registram 11 ou mais anos completos de estudo.

Os migrantes empregados como autônomos informais registram características domiciliares bastante diferenciadas em relação aos demais migrantes de rota rural-urbana. Nota-se maior presença de chefes de domicílio, famílias nucleares (cônjuges) e menores médias de trabalhadores e de migrantes chegados antes de 1995.

O menor rendimento médio do trabalho principal por hora (salário-hora) foi registrado para os migrantes ocupados como assalariados informais $(\mathrm{R} \$ 5,9)$, valor bem aquém da média observada para os migrantes empregados no meio urbano $(\mathrm{R} \$ 8,3)$. Por outro lado, os migrantes ocupados como autônomos informais aferiram rendimento médio de $\mathrm{R} \$ 10,4$ por hora, número que sugere importantes diferenças entre segmentos do próprio setor informal. Os dados também mostram que as médias de salário-hora nos setores formais também superam o rendimento dos migrantes assalariados informais, sobretudo quando se considera a remuneração no setor público $(\mathrm{R} \$ 14,1)$. Destarte, esta estrutura salarial parece ser bem consistente com as diferenças identificadas com respeito à idade (experiência) e ao nível de instrução também reportadas na tabela em foco. 
Tabela 1 - Estatísticas descritivas da amostra por condição de ocupação - migrantes rural-urbano (1995-2000)

\begin{tabular}{|c|c|c|c|c|c|}
\hline Variável & $\begin{array}{c}\text { Assalariado/ } \\
\text { autônomo formal }\end{array}$ & $\begin{array}{l}\text { Assalariado } \\
\text { informal }\end{array}$ & $\begin{array}{c}\text { Autônomo } \\
\text { informal }\end{array}$ & $\begin{array}{c}\text { Funcionário } \\
\text { público }\end{array}$ & Total \\
\hline \multicolumn{6}{|l|}{ Gênero* } \\
\hline mulher & $25,1 \%$ & $37,6 \%$ & $18,3 \%$ & $33,9 \%$ & $28,1 \%$ \\
\hline homem & $74,9 \%$ & $62,4 \%$ & $81,7 \%$ & $66,1 \%$ & $71,9 \%$ \\
\hline \multicolumn{6}{|l|}{ Raça* } \\
\hline não branco & $46,3 \%$ & $56,3 \%$ & $53,4 \%$ & $51,6 \%$ & $50,9 \%$ \\
\hline branco & $53,7 \%$ & $43,7 \%$ & $46,6 \%$ & $48,4 \%$ & $49,1 \%$ \\
\hline \multicolumn{6}{|l|}{ Experiência } \\
\hline Idade (média) & 30,43 & 32,60 & 36,43 & 33,77 & 32,24 \\
\hline idade2 (média) & $1.018,14$ & $1.180,11$ & $1.460,65$ & $1.238,51$ & $1.152,22$ \\
\hline \multicolumn{6}{|l|}{ Educação* } \\
\hline menos de 1 ano & $12,2 \%$ & $20,0 \%$ & $19,4 \%$ & $11,7 \%$ & $16,0 \%$ \\
\hline de 1 a 4 anos & $45,6 \%$ & $50,1 \%$ & $49,1 \%$ & $29,4 \%$ & $47,3 \%$ \\
\hline de 5 a 8 anos & $26,3 \%$ & $22,3 \%$ & $22,1 \%$ & $19,0 \%$ & $24,2 \%$ \\
\hline de 9 a 11 anos & $13,3 \%$ & $6,2 \%$ & $7,4 \%$ & $24,6 \%$ & $10,2 \%$ \\
\hline 12 ou mais & $2,5 \%$ & $1,3 \%$ & $2,0 \%$ & $15,3 \%$ & $2,3 \%$ \\
\hline \multicolumn{6}{|l|}{ Tempo de residência* } \\
\hline Menos de 1 ano & $12,4 \%$ & $16,4 \%$ & $13,7 \%$ & $15,3 \%$ & $14,0 \%$ \\
\hline 1 ano & $21,6 \%$ & $24,6 \%$ & $22,9 \%$ & $19,9 \%$ & $22,8 \%$ \\
\hline 2 anos & $20,9 \%$ & $20,5 \%$ & $21,1 \%$ & $20,1 \%$ & $20,8 \%$ \\
\hline 3 anos & $22,6 \%$ & $19,6 \%$ & $20,3 \%$ & $21,2 \%$ & $21,2 \%$ \\
\hline 4 anos & $22,4 \%$ & $18,9 \%$ & $22,0 \%$ & $23,5 \%$ & $21,2 \%$ \\
\hline \multicolumn{6}{|l|}{ Condição no domicílio* } \\
\hline não chefe & $41,0 \%$ & $49,6 \%$ & $30,6 \%$ & $38,4 \%$ & $41,9 \%$ \\
\hline chefe & $59,0 \%$ & $50,4 \%$ & $69,4 \%$ & $61,6 \%$ & $58,1 \%$ \\
\hline \multicolumn{6}{|l|}{ Estrutura do domicílio } \\
\hline moradores no domicílio (média) & 4,30 & 4,64 & 4,53 & 4,34 & 4,45 \\
\hline trabalhadores no domicílio (média) & 2,15 & 2,13 & 1,90 & 1,85 & 2,10 \\
\hline migrantes no domicílio (média) & 0,09 & 0,08 & 0,06 & 0,06 & 0,08 \\
\hline \multicolumn{6}{|l|}{ Situação conjugal* } \\
\hline não vive com cônjuge & $32,0 \%$ & $33,2 \%$ & $22,0 \%$ & $25,7 \%$ & $30,5 \%$ \\
\hline vive com cônjuge & $68,0 \%$ & $66,8 \%$ & $78,0 \%$ & $74,3 \%$ & $69,5 \%$ \\
\hline \multicolumn{6}{|l|}{ Rendimento do trabalho } \\
\hline salário-hora (média) & 8,83 & 5,98 & 10,43 & 14,06 & 8,30 \\
\hline \multicolumn{6}{|l|}{ Residência em 2000* } \\
\hline Norte & $7,5 \%$ & $15,3 \%$ & $22,4 \%$ & $30,2 \%$ & $13,1 \%$ \\
\hline Nordeste & $4,7 \%$ & $11,2 \%$ & $16,2 \%$ & $11,9 \%$ & $8,9 \%$ \\
\hline Sudeste & $56,6 \%$ & $43,2 \%$ & $32,2 \%$ & $27,2 \%$ & $47,4 \%$ \\
\hline Sul & $15,6 \%$ & $10,3 \%$ & $11,2 \%$ & $7,8 \%$ & $13,0 \%$ \\
\hline Centro-Oeste & $15,6 \%$ & $20,0 \%$ & $18,0 \%$ & $22,9 \%$ & $17,6 \%$ \\
\hline \multicolumn{6}{|l|}{ Residência em 1995* } \\
\hline Norte & $6,6 \%$ & $12,5 \%$ & $18,6 \%$ & $24,2 \%$ & $10,9 \%$ \\
\hline Nordeste & $41,7 \%$ & $41,0 \%$ & $36,0 \%$ & $26,3 \%$ & $40,2 \%$ \\
\hline Sudeste & $22,4 \%$ & $20,2 \%$ & $17,6 \%$ & $21,6 \%$ & $20,8 \%$ \\
\hline Sul & $20,6 \%$ & $14,0 \%$ & $14,7 \%$ & $12,7 \%$ & $17,3 \%$ \\
\hline Centro-Oeste & $8,8 \%$ & $12,3 \%$ & $13,1 \%$ & $15,1 \%$ & $10,8 \%$ \\
\hline Observações** & $11.859(48,4 \%)$ & $7.851(32,1 \%)$ & $4.316(17,6 \%)$ & $463(1,9 \%)$ & $24.489(100 \%)$ \\
\hline
\end{tabular}

Fonte: Elaboração própria a partir dos dados do Censo Demográfico de 2000.

Nota: * Variável qualitativa.

Observação:** É visualmente interessante deixar os percentuais abaixo dos totais conforme já se acha na coluna "autônomo informal". 
Os dados da Tabela 1 também revelam que a região Sudeste foi o principal destino dos trabalhadores migrantes no quinquênio 19952000, enquanto a região Nordeste destacou-se como a mais frequente região de origem. No entanto, quando se considera a distribuição geográfica dos migrantes de rota rural-urbana de acordo com distintas categorias de ocupação entre os setores formal e informal, notam-se diferenças marcantes. Neste sentido, observa-se, por um lado, que dentre os migrantes absorvidos no segmento formal privado, apenas $7 \%$ e $5 \%$ imigraram para as regióes Norte e Nordeste, respectivamente, e, por outro, que $57 \%$ foram absorvidos pela região Sudeste. Apesar da maior parcela desses migrantes ser originária da região Nordeste (42\%), 22\% emigraram da região Sudeste e 20\% da região Sul, ou seja, percentuais superiores àqueles registrados para a distribuição total.

Ao se analisar a distribuição regional dos migrantes ocupados como assalariados informais, apreende-se que nas regiões Centro-Oeste, Norte e Nordeste os percentuais de absorção superam as médias para o total dos migrantes, a despeito de a região Sudeste ter retido $43 \%$ dessa mão de obra. Do ponto de vista da região de origem, percebe-se que dentre os migrantes alocados no referido segmento informal, há relativa menor presença de trabalhadores oriundos da região Sul quando se compara a média total.

Já entre os migrantes empregados como autônomos informais ou como funcionários públicos, a distribuição da imigração regional é menos concentrada que nas demais categorias ocupacionais, sobretudo no tocante à região Sudeste, que perde força de atração relativamente às regiões Norte e Nordeste. Há também uma relativa desconcentração quanto à distribuição por região de origem, visto que as regiões Norte e Centro-Oeste ganham importância na emissão de trabalhadores alocados nos dois segmentos em foco.

Finalmente, as estatísticas da Tabela 1 também indicam que a presença de emigrantes rurais recém-chegados ao meio urbano é relativamente maior nos segmentos informais, ou seja, $41 \%$ dos assalariados informais e 37\% dos autônomos informais tinham até 1 ano de residência no município em 2000, valores acima dois percentuais de $34 \%$ e $35 \%$ observados, respectivamente, para os migrantes assalariados/autônomos formais e para os funcionários públicos. Tal distribuição parece ser consistente com a presença de barreiras ao 
emprego nos setores formais, reforçando a necessidade de uma investigação mais apropriada acerca da relação entre experiência de vida na cidade e transição do emigrante rural para a formalidade. A seguir, são apresentadas e discutidas as evidências empíricas resultantes da investigação levada a efeito neste trabalho.

\section{Evidências Empíricas}

Nesta seção, o foco é direcionado a duas das indagações feitas no início do trabalho. Mais especificamente, neste estágio, a preocupação é investigar como os níveis de escolaridade estão associados à alocação do migrante brasileiro da rota rural-urbana entre os setores do mercado de trabalho e, adicionalmente, se, no caso brasileiro, o setor informal urbano funciona como estágio intermediário para o ingresso do migrante saído do meio rural.

\subsection{Determinantes da Inserção Ocupacional do Migrante Rural-Urbano}

A seguir, a Tabela 2 reporta os resultados da estimação do modelo de escolha ocupacional na forma reduzida - Equação (3) por um logit multinomial. Os coeficientes apresentados referem-se às taxas relativas de risco (TRR), isto é, capturam os efeitos de uma mudança em determinado atributo sobre as chances de emprego em cada categoria ocupacional considerando por referência à alocação no emprego assalariado/autônomo formal (categoria base). ${ }^{19}$

${ }^{19}$ As estimativas foram feitas pelo método da Máxima Verossimilhança. As TRRs equivalem ao exponencial dos coeficientes obtidos para o modelo em foco, os quais podem ser encontrados na Tabela Al no apêndice. 
Tabela 2 - Brasil: Determinantes da escolha ocupacional do migrante rural-urbano - modelo multinomial na forma reduzida - taxa relativa de risco (categoria base - assalariado/autônomo formal)

\begin{tabular}{|c|c|c|c|}
\hline & Assalariado informal & Autônomo informal & Funcionário público \\
\hline \multirow{2}{*}{ homem } & $0,5162^{\star \star \star}$ & $1,2472^{\star \star \star}$ & $0,6133^{\star \star \star}$ \\
\hline & $(0,0202)$ & $(0,0698)$ & $(0,0808)$ \\
\hline \multirow{2}{*}{ branco } & $0,8399^{* \star *}$ & 1,0072 & 0,8713 \\
\hline & $(0,0270)$ & $(0,0399)$ & $(0,0915)$ \\
\hline \multirow{2}{*}{ idade } & 0,9849 & $1,0797^{\star \star \star}$ & $1,1239^{\star \star \star}$ \\
\hline & $(0,0093)$ & $(0,0122)$ & $(0,0344)$ \\
\hline \multirow{2}{*}{ idade2 } & $1,0004^{\star \star \star}$ & $0,9996^{\star \star \star}$ & $0,9989^{\star \star \star}$ \\
\hline & $(0,0001)$ & $(0,0001)$ & $(0,0004)$ \\
\hline \multirow{2}{*}{ educação de 1 a 4} & $0,7467^{\star \star \star}$ & 0,9696 & 0,8295 \\
\hline & $(0,0332)$ & $(0,0527)$ & $(0,1396)$ \\
\hline \multirow{2}{*}{ educação de 5 a 8} & $0,6018^{\star \star \star}$ & 0,9816 & 1,1057 \\
\hline & $(0,0312)$ & $(0,0631)$ & $(0,2089)$ \\
\hline \multirow{2}{*}{ educação de 9 a 11} & $0,2989^{\star \star \star}$ & $0,6768^{\star \star \star}$ & $2,8064^{\star \star \star}$ \\
\hline & $(0,0208)$ & $(0,0570)$ & $(0,5203)$ \\
\hline \multirow{2}{*}{ educação 12 ou mais } & $0,3277^{\star \star *}$ & $0,6536^{\star \star \star}$ & $7,0327^{\star \star \star}$ \\
\hline & $(0,0412)$ & $(0,0912)$ & $(1,4224)$ \\
\hline \multirow{2}{*}{ Norte (destino) } & $2,3951^{\star \star \star}$ & $3,6135^{\star \star \star}$ & $6,4036^{\star \star \star}$ \\
\hline & $(0,1606)$ & $(0,2775)$ & $(1,2017)$ \\
\hline \multirow{2}{*}{ Nordeste (destino) } & $2,9858^{\star \star \star}$ & $5,3126^{\star \star \star}$ & $5,5048^{\star \star \star}$ \\
\hline & $(0,1865)$ & $(0,3753)$ & $(1,0785)$ \\
\hline \multirow{2}{*}{ Sul (destino) } & 0,9542 & 1,0245 & 0,8514 \\
\hline & $(0,0655)$ & $(0,0853)$ & $(0,1857)$ \\
\hline \multirow{2}{*}{ Centro-Oeste (destino) } & $1,5384^{* \star *}$ & $1,5168^{* \star *}$ & $2,4450^{\star * *}$ \\
\hline & $(0,0759)$ & $(0,0979)$ & $(0,3991)$ \\
\hline \multirow{2}{*}{ Norte (origem) } & $1,2843^{\star \star \star}$ & $1,5172^{\star \star \star}$ & $2,0177^{\star \star \star}$ \\
\hline & $(0,0912)$ & $(0,1200)$ & $(0,3781)$ \\
\hline \multirow{2}{*}{ Sudeste (origem) } & $1,2170^{\star \star \star}$ & $1,2294^{\star \star \star}$ & $2,0854^{\star \star \star}$ \\
\hline & $(0,0524)$ & $(0,0706)$ & $(0,3345)$ \\
\hline \multirow{2}{*}{ Sul (origem) } & 1,0451 & 1,1281 & $1,5057^{\star *}$ \\
\hline & $(0,0671)$ & $(0,0895)$ & $(0,2941)$ \\
\hline \multirow{2}{*}{ Centro-Oeste (origem) } & $1,4280^{\star \star \star}$ & $1,5713^{\star \star \star}$ & $1,9351^{\star \star \star}$ \\
\hline & $(0,0873)$ & $(0,1180)$ & $(0,3575)$ \\
\hline \multirow{2}{*}{ chefe } & $0,7652^{\star \star \star}$ & $0,8316^{\star \star \star}$ & 0,8958 \\
\hline & $(0,0312)$ & $(0,0450)$ & $(0,1227)$ \\
\hline \multirow{2}{*}{ casado } & $0,8489^{\star \star *}$ & $1,1105^{\star \star}$ & 1,1486 \\
\hline & $(0,0307)$ & $(0,0547)$ & $(0,1360)$ \\
\hline \multirow{2}{*}{ moradores no domicílio } & $1,0519^{\star \star \star}$ & $1,0319^{\star \star *}$ & $1,0487^{\star}$ \\
\hline & $(0,0089)$ & $(0,0109)$ & $(0,0287)$ \\
\hline \multirow{2}{*}{ trabalhadores no domicilio } & $0,9179^{\star \star \star}$ & $0,8724^{\star \star \star}$ & $0,8453^{\star \star \star}$ \\
\hline & $(0,0127)$ & $(0,0168)$ & $(0,0506)$ \\
\hline \multirow{2}{*}{ migrantes no domicílio } & $0,9322^{*}$ & 0,9989 & 0,9357 \\
\hline & $(0,0336)$ & $(0,0525)$ & $(0,1267)$ \\
\hline Pseudo R2 & 0,0827 & & \\
\hline Número de observações & 24.489 & & \\
\hline
\end{tabular}

Fonte: Elaboração própria a partir dos dados do Censo Demográfico de 2000.

Notas: Categoria de referência: setor formal privado. Desvios padrão robustos entre parênteses. ${ }^{* * *}$ Estatisticamente significante a $1 \% .{ }^{* *}$ Estatisticamente significante a $5 \% .{ }^{*}$ Estatisticamente significante a $10 \%$. 
Em geral, os resultados revelam diferenças importantes no tocante ao impacto dos atributos referentes ao gênero, idade e instrução sobre a alocação dos migrantes entre as categorias de ocupação estudadas. Nota-se, por exemplo, que, comparativamente ao ingresso no segmento formal privado (base da TRR), os homens registram $25 \%$ $(1,2472-1)$ a mais de chance de alocação no trabalho autônomo informal que as mulheres (categoria de referência), por um lado, e, por outro, riscos 48\% (0,5162 - 1) e 39\% (0,6133 - 1) menores quando se considera a inserção nas categorias assalariado informal ou funcionário público, respectivamente. Já a raça parece ser relevante apenas para a distribuição dos migrantes de rota rural-urbana entre as categorias assalariado informal e assalariado/autônomo formal, uma vez que os trabalhadores de cor branca têm menor chance relativa de ingressar na primeira categoria ( $16 \%$ a menos).

Quanto às características relacionadas ao estoque individual de capital humano, de particular interesse, nota-se que estas exercem influências decisivas na alocação ocupacional do migrante. Primeiro, perceba-se que indivíduos com mais experiência (mais idade) apresentam maiores chances de inserção nas categorias autônomo informal e funcionário público, em relação ao ingresso no setor formal privado. Ou seja, os riscos estimados são $8 \%$ e $12 \%$ maiores, respectivamente, para o primeiro e segundo casos. Tais evidências são consistentes com a necessidade de maior formação e treinamento para o ingresso no setor público brasileiro e com exigências de capital inicial, em geral, para o trabalho como informal autônomo.

Os resultados presentes na Tabela 2 também indicam que os migrantes mais escolarizados apresentam maiores chances de inserção nos segmentos formais que informais, ou seja, uma evidência em linha com aquela obtida por Meng (2001) para o caso da China. Por exemplo, um migrante com 12 ou mais anos de estudo tem $67 \%$ a menos de chance relativa de se encontrar trabalhando como assalariado informal, quando comparado a um migrante com menos de 1 ano de estudo (categoria omitida). Contudo, é importante observar que dentro do setor formal, níveis mais altos de escolaridade influenciam positivamente as chances do emprego no setor público em relação ao formal privado; para os grupos de migrantes com 9 a 11 anos de estudo e 12 ou mais, por exemplo, os riscos de ingresso no setor público são $181 \%$ e $603 \%$ maiores que no formal privado, considerando por base o migrante analfabeto. Por outro lado, nota-se que quanto 
maior a faixa de instrução do migrante rural-urbano, menor é a propensão de o mesmo trabalhar como assalariado informal. Ademais, ao contrário, dos resultados obtidos por Meng (2001), no caso brasileiro, níveis de escolaridade mais elevados diminuem as chances de ingresso no setor informal autônomo em relação à inserção no setor privado. $^{20}$ Tal conjunto de evidências sugere que, no Brasil, a escolaridade é uma característica importante no sentido de diferenciar as chances de alocação do migrante rural-urbano entre os segmentos formais e informais.

Há, também, um padrão diferenciado de inserção dos migrantes entre os diferentes segmentos do mercado de trabalho, de acordo com as regiões de destino, o que, por seu turno, reflete, em boa medida, as diferenças entre as regiões com respeito à estrutura do mercado de trabalho. Assim, em relação à região Sudeste (categoria de referência), nota-se que os migrantes que se destinam às regiões Norte, Nordeste e Centro-Oeste (mais pobres) apresentam mais chances de inserção nos segmentos informais e público que no setor formal privado. No tocante às regiões de origem percebe-se, por exemplo, comparativamente aos emigrantes rurais da região Nordeste (categoria omitida), que aqueles oriundos das demais regiões são mais propensos ao ingresso no setor público, sobretudo os trabalhadores oriundos da região Sudeste. Note-se ainda que ao se comparar o risco relativo de inserção nos empregos informais (assalariado ou autônomo), os emigrantes das regiões Norte, Centro-Oeste e Sudeste são mais favorecidos, no entanto, as chances aumentam menos para aqueles que em 1995 se achavam no meio rural do Sudeste. ${ }^{21}$ Uma vez que essas variáveis procuram controlar efeitos não observados e relacionados ao capital humano absorvido no local de origem do migrante, os achados reportados parecem guardar consistência com as conhecidas desigualdades regionais de capital humano no Brasil.

Finalmente, as variáveis usadas para identificar o modelo revelaram, em sua maioria, coeficientes estatisticamente significativos. Destacam-se as influências assimétricas do número de moradores e de trabalhadores no domicílio. Enquanto a primeira característica

\footnotetext{
${ }^{20}$ Uma possível justificativa para tal resultado seria que a maior escolaridade do migrante pode favorecer a formalização do trabalho autônomo.

${ }^{21}$ Foram testadas regressões incluindo dummies interadas de origem e de destino. No entanto, essas variáveis além de se revelarem estatisticamente significativas, prejudicaram bastante a significância das dummies regionais. Por esse motivo, optou-se por não incluí-las na especificação do modelo.
} 
aumenta as chances relativas de emprego nos três setores explicitados, relativamente à inserção no segmento formal privado, a segunda reduz. A presença de cônjuge no domicílio do migrante (família nuclear) diminui (aumenta) o risco relativo de emprego assalariado (autônomo) informal. O fato de o migrante ser chefe de domicílio, por sua vez, reduz a chance relativa de emprego nos segmentos informais. Já o maior número de migrantes interestaduais chegados antes de 1995 e que residem no mesmo domicílio do migrante rural-urbano, parece desfavorecer o emprego assalariado informal relativo ao ingresso no setor formal privado. ${ }^{22}$

\subsection{Determinantes do Rendimento do Trabalho e Autosseleção}

Com o intuito de se investigar os determinantes dos rendimentos dos migrantes rural-urbano de acordo com a alocação ocupacional desses trabalhadores nas cidades brasileiras, foram realizadas, a seguir, regressões de salários (mincerianas) em amostras separadas por condição do migrante na ocupação. As informações presentes na Tabela 3, a seguir, permitem, por um lado, comparar os coeficientes estimados com e sem correção para potencial viés de seleção amostral (vide Equações (2) e (4)) e, por outro, avaliar o padrão de autosseleção dos migrantes em atributos não observados.

Em linhas gerais, segundo os dados da Tabela 3, nota-se que há significativas diferenças em muitos coeficientes entre as estimativas com correção e sem correção para viés de seleção, sobretudo, no tocante àqueles relacionados ao gênero, instrução e região de residência. Nesse sentido, considerando as variáveis de correção obtidas na regressão do modelo de seleção em primeiro estágio - vide Equação (3), os achados revelam coeficiente negativo (positivo) para os migrantes ocupados como assalariados (autônomos) informais. Isto indica que, dados os atributos observados para a primeira categoria, os salários-hora devem ser menores que aqueles de indivíduos escolhidos aleatoriamente no total da amostra; já para aqueles empregados como autônomos informais, os salários seriam mais altos. Logo, há forte evidência de diferenças na seletividade dos migrantes

${ }^{22} \mathrm{Tal}$ achado pode estar relacionado ao efeito das redes sociais, uma vez que o contato com pessoas conhecidas no lugar de destino pode reduzir os custos da migração e da procura por emprego. Em alguns casos, por exemplo, o trabalhador já poderia migrar com um contrato de trabalho estabelecido.

Est. Econ., São Paulo, vol. 42, n.4, p. 731-771, out.-dez. 2012 
dentro do próprio setor informal, ou seja, o migrante típico alocado como assalariado informal parece ser negativamente selecionado em atributos produtivos não observados, enquanto o migrante autônomo informal, positivamente selecionado.

Tabela 3 - Regressões de salários-hora (em logaritmo) com e sem correção para viés de seleção na amostra - migrantes rural-urbano

\begin{tabular}{|c|c|c|c|c|c|c|c|c|}
\hline & \multicolumn{2}{|c|}{$\begin{array}{c}\text { Assalariado/ } \\
\text { autônomo formal }\end{array}$} & \multicolumn{2}{|c|}{$\begin{array}{l}\text { Assalariado } \\
\text { informal }\end{array}$} & \multicolumn{2}{|c|}{$\begin{array}{l}\text { Autônomo } \\
\text { informal }\end{array}$} & \multicolumn{2}{|c|}{$\begin{array}{l}\text { Funcionário } \\
\text { público }\end{array}$} \\
\hline & $\begin{array}{c}\text { Não } \\
\text { corrigida }\end{array}$ & Corrigida & $\begin{array}{c}\text { Não } \\
\text { corrigida }\end{array}$ & Corrigida & $\begin{array}{c}\text { Não } \\
\text { corrigida }\end{array}$ & Corrigida & $\begin{array}{c}\text { Não } \\
\text { corrigida }\end{array}$ & Corrigida \\
\hline homem & $\begin{array}{c}0,2714^{\star \star *} \\
(0,0116)\end{array}$ & $\begin{array}{c}0,2516^{\star \star \star} \\
(0,0235)\end{array}$ & $\begin{array}{c}0,2726^{\star \star \star} \\
(0,0151)\end{array}$ & $\begin{array}{c}0,0070 \\
(0,0365)\end{array}$ & $\begin{array}{c}0,2923^{\star \star \star} \\
(0,0364)\end{array}$ & $\begin{array}{c}0,2032^{* \star *} \\
(0,0614)\end{array}$ & $\begin{array}{c}0,2639^{\star \star *} \\
(0,0667)\end{array}$ & $\begin{array}{l}0,3132^{\star \star \star} \\
(0,0848)\end{array}$ \\
\hline branco & $\begin{array}{c}0,0900^{* \star *} \\
(0,0107)\end{array}$ & $\begin{array}{c}0,0855^{\star \star \star} \\
(0,0118)\end{array}$ & $\begin{array}{c}0,0989^{\star \star \star} \\
(0,0155)\end{array}$ & $\begin{array}{l}0,0400^{\star *} \\
(0,0163)\end{array}$ & $\begin{array}{c}0,1606^{\star \star \star} \\
(0,0283)\end{array}$ & $\begin{array}{c}0,1448^{\star \star \star} \\
(0,0310)\end{array}$ & $\begin{array}{c}0,0281 \\
(0,0668)\end{array}$ & $\begin{array}{c}0,0424 \\
(0,0661)\end{array}$ \\
\hline idade & $\begin{array}{c}0,0344^{\star \star *} \\
(0,0039)\end{array}$ & $\begin{array}{c}0,0346^{\star * \star} \\
(0,0039)\end{array}$ & $\begin{array}{c}0,0228^{\star \star \star} \\
(0,0043)\end{array}$ & $\begin{array}{l}0,0101^{\star *} \\
(0,0047)\end{array}$ & $\begin{array}{l}0,0146^{*} \\
(0,0075)\end{array}$ & $\begin{array}{c}0,0004 \\
(0,0111)\end{array}$ & $\begin{array}{l}0,0407^{\star \star} \\
(0,0173)\end{array}$ & $\begin{array}{c}0,0143 \\
(0,0280)\end{array}$ \\
\hline idade2 & $\begin{array}{c}-0,0004^{* * *} \\
(0,0001)\end{array}$ & $\begin{array}{c}-0,0004^{* \star *} \\
(0,0001)\end{array}$ & $\begin{array}{c}-0,0003^{\star \star \star} \\
(0,0001)\end{array}$ & $\begin{array}{c}-0,0002^{* * *} \\
(0,0001)\end{array}$ & $\begin{array}{l}-0,0002^{\star *} \\
(0,0001)\end{array}$ & $\begin{array}{l}-0,0001 \\
(0,0001)\end{array}$ & $\begin{array}{l}-0,0005^{\star *} \\
(0,0002)\end{array}$ & $\begin{array}{l}-0,0002 \\
(0,0003)\end{array}$ \\
\hline educação de 1 a 4 & $\begin{array}{c}0,1660^{\star * *} \\
(0,0161)\end{array}$ & $\begin{array}{c}0,1577^{\star \star \star} \\
(0,0180)\end{array}$ & $\begin{array}{c}0,1279^{\star \star \star} \\
(0,0198)\end{array}$ & $\begin{array}{c}0,0363 \\
(0,0224)\end{array}$ & $\begin{array}{c}0,2921^{\star \star \star} \\
(0,0364)\end{array}$ & $\begin{array}{c}0,2732^{\star \star \star} \\
(0,0394)\end{array}$ & $\begin{array}{c}0,0716 \\
(0,1085)\end{array}$ & $\begin{array}{c}0,0844 \\
(0,1061)\end{array}$ \\
\hline educação de 5 a 8 & $\begin{array}{c}0,3022^{\star \star *} \\
(0,0182)\end{array}$ & $\begin{array}{c}0,2889^{* * *} \\
(0,0225)\end{array}$ & $\begin{array}{c}0,2813^{\star \star \star} \\
(0,0247)\end{array}$ & $\begin{array}{l}0,1120^{* * *} \\
(0,0323)\end{array}$ & $\begin{array}{c}0,4789^{\star \star \star} \\
(0,0447)\end{array}$ & $\begin{array}{c}0,4445^{\star * *} \\
(0,0484)\end{array}$ & $\begin{array}{c}0,4635^{\star * *} \\
(0,1263)\end{array}$ & $\begin{array}{c}0,4036^{\star \star \star} \\
(0,1319)\end{array}$ \\
\hline educação de 9 a 11 & $\begin{array}{c}0,5479^{\star \star *} \\
(0,0230)\end{array}$ & $\begin{array}{c}0,5169^{* * *} \\
(0,0388)\end{array}$ & $\begin{array}{l}0,4818^{\star \star \star} \\
(0,0397)\end{array}$ & $\begin{array}{c}0,0944 \\
(0,0629)\end{array}$ & $\begin{array}{l}0,6909^{\star * *} \\
(0,0610)\end{array}$ & $\begin{array}{c}0,6892^{\star \star *} \\
(0,0620)\end{array}$ & $\begin{array}{l}1,0733^{\star * *} \\
(0,1228)\end{array}$ & $\begin{array}{r}0,7694^{\star * \star} \\
(0,2849)\end{array}$ \\
\hline educação 12 ou mais & $\begin{array}{l}1,1821^{* * *} \\
(0,0629)\end{array}$ & $\begin{array}{l}1,1587^{\star * *} \\
(0,0677)\end{array}$ & $\begin{array}{l}0,2610^{\star * *} \\
(0,0944)\end{array}$ & $\begin{array}{l}-0,1218 \\
(0,1051)\end{array}$ & $\begin{array}{c}1,0166^{* * *} \\
(0,1296)\end{array}$ & $\begin{array}{l}1,0381^{\star * *} \\
(0,1304)\end{array}$ & $\begin{array}{l}1,7058^{\star * *} \\
(0,1523)\end{array}$ & $\begin{array}{l}1,1906^{\star * *} \\
(0,4520)\end{array}$ \\
\hline Norte (destino) & $\begin{array}{c}-0,1459^{\star * *} \\
(0,0294)\end{array}$ & $\begin{array}{l}-0,1009^{*} \\
(0,0525)\end{array}$ & $\begin{array}{c}-0,3445^{\star \star \star} \\
(0,0302)\end{array}$ & $\begin{array}{c}-0,1973^{\star \star \star} \\
(0,0358)\end{array}$ & $\begin{array}{c}-0,1450^{\star \star \star} \\
(0,0536)\end{array}$ & $\begin{array}{c}-0,2863^{\star \star \star} \\
(0,1005)\end{array}$ & $\begin{array}{l}-0,0664 \\
(0,1143)\end{array}$ & $\begin{array}{l}-0,3373 \\
(0,2653)\end{array}$ \\
\hline Nordeste (destino) & $\begin{array}{c}-0,3381^{* * *} \\
(0,0347)\end{array}$ & $\begin{array}{c}-0,2808^{\star \star \star} \\
(0,0644)\end{array}$ & $\begin{array}{c}-0,6184^{* \star \star} \\
(0,0281)\end{array}$ & $\begin{array}{c}-0,4478^{\star * *} \\
(0,0363)\end{array}$ & $\begin{array}{c}-0,5449^{\star * *} \\
(0,0465)\end{array}$ & $\begin{array}{c}-0,7306^{\star \star \star} \\
(0,1229)\end{array}$ & $\begin{array}{l}-0,2796^{\star \star} \\
(0,1217)\end{array}$ & $\begin{array}{r}-0,4829^{\star *} \\
(0,2216)\end{array}$ \\
\hline Sul (destino) & $\begin{array}{c}-0,1272^{\star * *} \\
(0,0214)\end{array}$ & $\begin{array}{c}-0,1281^{\star \star \star} \\
(0,0217)\end{array}$ & $\begin{array}{c}-0,2540^{\star \star \star} \\
(0,0341)\end{array}$ & $\begin{array}{c}-0,2554^{\star \star *} \\
(0,0331)\end{array}$ & $\begin{array}{c}-0,1903^{\star \star \star} \\
(0,0646)\end{array}$ & $\begin{array}{c}-0,2022^{\star \star \star} \\
(0,0653)\end{array}$ & $\begin{array}{l}-0,1280 \\
(0,2016)\end{array}$ & $\begin{array}{l}-0,1054 \\
(0,2034)\end{array}$ \\
\hline Centro-Oeste (destino) & $\begin{array}{c}-0,1510^{\star \star *} \\
(0,0166)\end{array}$ & $\begin{array}{c}-0,1337^{\star \star \star} \\
(0,0231)\end{array}$ & $\begin{array}{c}-0,2162^{\star \star \star} \\
(0,0221)\end{array}$ & $\begin{array}{c}-0,1027^{\star \star *} \\
(0,0267)\end{array}$ & $\begin{array}{l}-0,0579 \\
(0,0463)\end{array}$ & $\begin{array}{l}-0,0990^{*} \\
(0,0525)\end{array}$ & $\begin{array}{l}-0,0034 \\
(0,1088)\end{array}$ & $\begin{array}{l}-0,1494 \\
(0,1629)\end{array}$ \\
\hline Norte (origem) & $\begin{array}{c}0,0228 \\
(0,0312)\end{array}$ & $\begin{array}{c}0,0368 \\
(0,0334)\end{array}$ & $\begin{array}{c}0,0350 \\
(0,0319)\end{array}$ & $\begin{array}{c}0,0536^{*} \\
(0,0317)\end{array}$ & $\begin{array}{c}0,0423 \\
(0,0541)\end{array}$ & $\begin{array}{l}-0,0031 \\
(0,0597)\end{array}$ & $\begin{array}{c}0,1604 \\
(0,1172)\end{array}$ & $\begin{array}{c}0,0581 \\
(0,1407)\end{array}$ \\
\hline Sudeste (origem) & $\begin{array}{l}-0,0147 \\
(0,0131)\end{array}$ & $\begin{array}{l}-0,0068 \\
(0,0149)\end{array}$ & $\begin{array}{c}-0,1280^{* \star \star} \\
(0,0207)\end{array}$ & $\begin{array}{c}-0,0801^{* * *} \\
(0,0203)\end{array}$ & $\begin{array}{c}0,0578 \\
(0,0404)\end{array}$ & $\begin{array}{c}0,0370 \\
(0,0395)\end{array}$ & $\begin{array}{l}0,2145^{\star *} \\
(0,0960)\end{array}$ & $\begin{array}{c}0,1025 \\
(0,1304)\end{array}$ \\
\hline Sul (origem) & $\begin{array}{l}0,0408^{*} \\
(0,0212)\end{array}$ & $\begin{array}{l}0,0429^{* *} \\
(0,0214)\end{array}$ & $\begin{array}{c}0,0215 \\
(0,0319)\end{array}$ & $\begin{array}{c}0,0189 \\
(0,0310)\end{array}$ & $\begin{array}{c}0,0694 \\
(0,0619)\end{array}$ & $\begin{array}{c}0,0582 \\
(0,0618)\end{array}$ & $\begin{array}{c}0,1426 \\
(0,1713)\end{array}$ & $\begin{array}{c}0,0886 \\
(0,1843)\end{array}$ \\
\hline Centro-Oeste (origem) & $\begin{array}{c}0,0210 \\
(0,0226)\end{array}$ & $\begin{array}{c}0,0367 \\
(0,0274)\end{array}$ & $\begin{array}{l}-0,0345 \\
(0,0272)\end{array}$ & $\begin{array}{c}0,0283 \\
(0,0270)\end{array}$ & $\begin{array}{c}0,0590 \\
(0,0541)\end{array}$ & $\begin{array}{c}0,0105 \\
(0,0622)\end{array}$ & $\begin{array}{c}0,0784 \\
(0,1177)\end{array}$ & $\begin{array}{l}-0,0003 \\
(0,1380)\end{array}$ \\
\hline$\lambda$ & & $\begin{array}{l}0,1020 \\
(0,0997)\end{array}$ & & $\begin{array}{c}-0,7564^{\star * *} \\
(0,0941)\end{array}$ & & $\begin{array}{l}0,3634^{*} \\
(0,2160)\end{array}$ & & $\begin{array}{l}0,5378 \\
(0,4601)\end{array}$ \\
\hline intercepto & $\begin{array}{c}0,8900^{* * *} \\
(0,0663)\end{array}$ & $\begin{array}{c}0,9653^{\star \star *} \\
(0,1019)\end{array}$ & $\begin{array}{c}0,9980^{* * *} \\
(0,0783)\end{array}$ & $\begin{array}{c}0,6559^{* * *} \\
(0,0857)\end{array}$ & $\begin{array}{c}1,0715^{\star * *} \\
(0,1498)\end{array}$ & $\begin{array}{c}2,1102^{\star \star *} \\
(0,6253)\end{array}$ & $\begin{array}{l}0,5852^{*} \\
(0,3326) \\
\end{array}$ & $\begin{array}{r}2,6090 \\
(1,7331) \\
\end{array}$ \\
\hline R2 ajustado & 0,1715 & 0,1715 & 0,1483 & 0,1544 & 0,1394 & 0,1398 & 0,4609 & 0,4614 \\
\hline Número de observações & 11.859 & 11.859 & 7.851 & 7.851 & 4.316 & 4.316 & 463 & 463 \\
\hline
\end{tabular}

Fonte: Elaboração própria a partir dos dados do Censo Demográfico de 2000.

Notas: Desvios padrão robustos entre parênteses e para regressões corrigidas foram obtidos por bootstrap com 1.000 replicações. ${ }^{* * *}$ Estatisticamente significante a $1 \% .{ }^{* *}$ Estatisticamente significante a 5\%. ${ }^{*}$ Estatisticamente significante a $10 \%$. 
De acordo com os parâmetros estimados para as características pessoais, os migrantes homens e de raça branca, de forma geral, recebem maiores remunerações que as mulheres e trabalhadores não brancos, independentemente das ocupações consideradas, ainda que, após o controle para atributos não observados, essas diferenças sejam bem menores para os assalariados informais, o que provavelmente decorre dos níveis gerais mais baixos destas remunerações. Quanto às variáveis de capital humano, os efeitos estão de acordo com as expectativas: trabalhadores migrantes mais escolarizados e com mais experiência, independentemente da inserção ocupacional observada, recebem maiores salários, embora, novamente, as diferenças observadas sejam menores para os migrantes ocupados como assalariados informais. Os resultados também confirmam as expectativas de rendimentos menores quando o destino é a região Norte ou a região Nordeste (mais pobres), considerando a região Sudeste como referência. Mesmo para os migrantes empregados no setor público, a residência na região Nordeste, em média, está associada a salários inferiores àqueles recebidos pelos migrantes que se dirigiram ao Sudeste. Poucas diferenças de rendimentos podem ser atribuídas às regiões de origem, exceto no caso dos trabalhadores empregados como assalariados/autônomos formais e assalariados informais. Comparados aos migrantes oriundos da região Nordeste (categoria de referência), aqueles que emigraram da região Sul e se ocuparam no setor formal receberam, em média, um salário-hora maior, ao passo que os emigrantes da região Sudeste ocupados como assalariados informais auferiam um salário menor.

\subsection{Transição no Mercado de Trabalho e Racionalidade do Migrante}

Nessa etapa de investigação, passa-se a explorar com maior propriedade como o tempo de residência na cidade se relaciona com a alocação ocupacional do migrante rural-urbano no Brasil, assim como se a inserção do migrante em determinado segmento do mercado de trabalho é consistente com a diferença esperada de salário em caso de transição para outra ocupação (retorno econômico). Note-se que, por um lado, tal expediente permite investigar o papel do setor informal para a viabilidade da migração rural-urbana e, por outro, evidenciar a racionalidade da escolha feita pelo migrante e/ou a existência de barreiras à entrada nas diferentes categorias ocupacionais. 
O primeiro exercício contrafactual foi baseado no ajuste de duas regressões logit multinomial considerando Equação de seleção ocupacional (3) e amostras separadas de acordo com o tempo de residência do migrante rural-urbano no município, ou seja, uma regressão para migrantes recém-chegados à cidade (até 1 ano de residência) e outra para os migrantes mais experientes (de 3 a 4 anos de moradia), já considerando as influências de várias características observadas. Destarte, levando-se em conta as predições de probabilidades de ocupação dentro e fora de cada amostra, juntamente com as dotações de atributos dos migrantes recém-chegados, a Equação (5) permitiu computar a diferença entre a probabilidade contrafactual e factual para cada categoria ocupacional. A primeira refere-se à probabilidade de o migrante recém-chegado se encontrar na mesma ocupação atual caso houvesse registrado de 3 a 4 anos no meio urbano, enquanto a segunda é a probabilidade condicionada de o mesmo trabalhador se encontrar na ocupação atual. Por fim, foram tomadas as médias das referidas diferenças de probabilidade por faixas de escolaridade. A Figura 1, abaixo, apresenta tais resultados. ${ }^{23}$

Conforme pode ser constatado, as diferenças positivas (negativas) de probabilidade de ocupação assalariada/autônoma formal (assalariada informal) indicam que a experiência na cidade parece favorecer a transição do migrante do setor informal para o emprego formal no setor privado. Note-se ainda que, em média, as diferenças reportadas são crescentes (em valor absoluto) com o grau de instrução, sobretudo, até os 8 anos de escolaridade. Desta forma, as evidências obtidas sugerem que níveis de escolaridade mais elevados não só permitem maiores chances de inserção no segmento formal privado para o migrante inicialmente alocado como assalariado informal, um resultado semelhante ao obtido por Banerjee (1983) para o caso da Índia, como também parece possibilitar mais rápida mobilidade entre estes segmentos. Tais resultados ainda são consoantes com a perspectiva original de Cole e Sanders (1985), que destacam a importância dos diferenciais de capital humano e do papel do setor informal como intermediário e transitório no processo de migração rural-urbana.

\footnotetext{
${ }^{23}$ Os migrantes experientes podem ser trabalhadores mais seletivos que conseguiram sobreviver ao mercado de trabalho no período de migração analisado. Todavia, a Tabela A.2, no apêndice, registra as estatísticas descritivas das variáveis usadas nos modelos empíricos considerando a ocupação e tempo de residência na cidade. Os dados mostram que, dentre os grupos de ocupação, os atributos de idade e de instrução, sobretudo, são bastante semelhantes entre os migrantes recém-chegados às cidades e os mais experientes, o que reforça as evidências reportadas na Figura 1.
} 


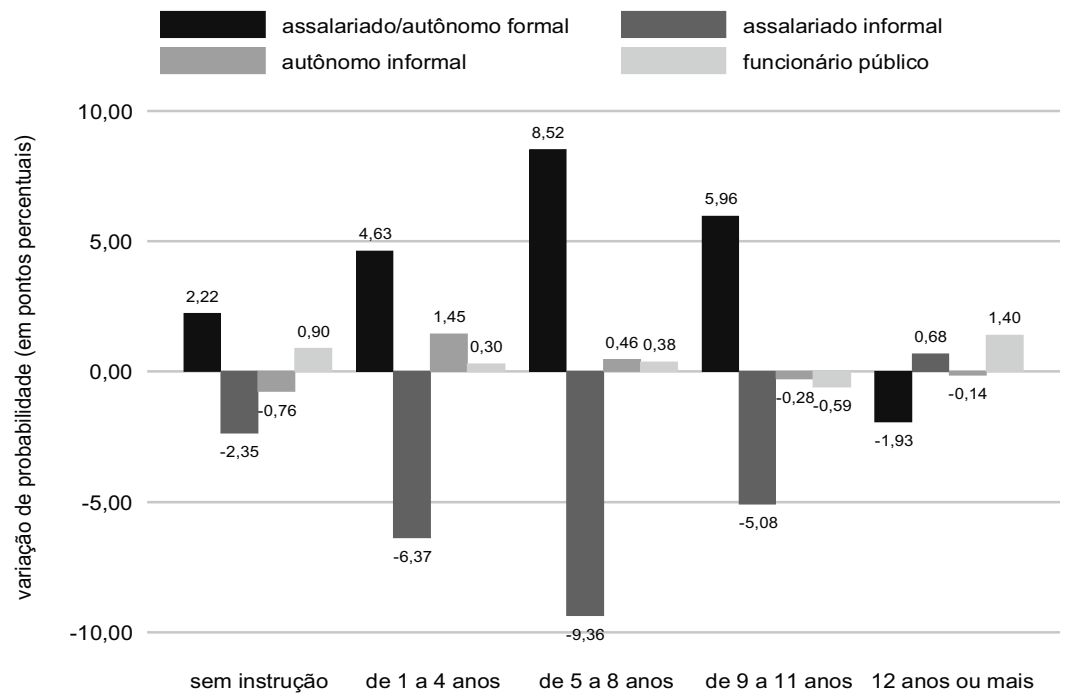

Figura 1 - Diferencial de probabilidade contrafactual/factual de emprego segundo categorias de ocupação e por faixas de escolaridade - migrantes rural urbano com até 1 ano de residência na cidade

Fonte: Elaboração própria a partir dos dados do Censo Demográfico de 2000.

Nota: Contrafactual - caso de permanência de 3 a 4 anos na cidade.

Por outro lado, as evidências também sugerem que o tempo de residência do migrante rural-urbano na cidade não induz a troca do emprego autônomo informal, dadas as pequenas diferenças de probabilidade contrafactual e factual. Desta forma, tais achados parecem corroborar a hipótese da necessidade de aquisição de habilidades específicas para o ingresso nessa ocupação, por um lado, e podem estar relacionados à menor precariedade nas relações de trabalho quando comparada ao emprego assalariado informal, por outro. Ainda conforme os dados da Figura 1, percebe-se que a experiência na cidade parece não contribuir efetivamente para o ingresso do migrante rural-urbano no setor público, exceto para os migrantes recém-chegados com 12 ou mais anos de estudo, cuja diferença de probabilidade contrafactual/factual é 1,4 ponto percentual. Tal resultado específico é consistente com a exigência de mais elevado grau de instrução formal, em geral, para inserção no setor em foco.

A Tabela 4, a seguir, registra a decomposição da diferença de salários-hora entre migrantes rural-urbano alocados em distintas catego- 
rias de ocupação formal e informal. Esses resultados foram obtidos através da Equação (6) e consideram os coeficientes das regressões de salários corrigidos para viés de seleção amostral.

Tabela 4 - Decomposição Blinder-Oaxaca - diferencial de salários por categoria de ocupação dos migrantes de rota rural-urbana

\begin{tabular}{|c|c|c|c|c|}
\hline \multirow{2}{*}{$\begin{array}{l}\text { assalariado informal versus } \\
\text { assalariado/autônomo formal }\end{array}$} & \multicolumn{2}{|c|}{ assalariado/autônomo formal (base) } & \multicolumn{2}{|c|}{ assalariado informal (base) } \\
\hline & valor & $\%$ & valor & $\%$ \\
\hline diferencial total & $\begin{array}{c}-1,2851^{\star \star *} \\
(0,1246)\end{array}$ & 100,0 & $\begin{array}{l}1,2851^{\star \star \star} \\
(0,1246)\end{array}$ & 100,0 \\
\hline parcela explicada & $\begin{array}{c}-0,0495^{\star \star \star} \\
(0,0141)\end{array}$ & 3,9 & $\begin{array}{l}0,1148^{\star \star \star} \\
(0,0165)\end{array}$ & 8,9 \\
\hline parcela não explicada & $\begin{array}{c}-1,2356^{\star \star \star} \\
(0,1355)\end{array}$ & 96,1 & $\begin{array}{l}1,1702^{\star \star \star} \\
(0,1343)\end{array}$ & 91,1 \\
\hline $\begin{array}{l}\text { assalariado informal } \\
\text { versus autônomo informal }\end{array}$ & \multicolumn{2}{|c|}{ autônomo informal (base) } & \multicolumn{2}{|c|}{ assalariado informal (base) } \\
\hline & valor & $\%$ & valor & $\%$ \\
\hline diferencial total & $\begin{array}{c}-1,5976^{\star \star \star} \\
(0,3067)\end{array}$ & 100,0 & $\begin{array}{l}1,5976^{\star \star \star} \\
(0,3067)\end{array}$ & 100,0 \\
\hline parcela explicada & $\begin{array}{l}0,0379^{\star * \star} \\
(0,0082)\end{array}$ & $-2,4$ & $\begin{array}{l}-0,0269 \\
(0,0383)\end{array}$ & $-1,7$ \\
\hline parcela não explicada & $\begin{array}{c}-1,6355^{\star \star *} \\
(0,3087)\end{array}$ & 102,4 & $\begin{array}{l}1,6245^{\star \star \star} \\
(0,3412)\end{array}$ & 101,7 \\
\hline $\begin{array}{l}\text { assalariado informal } \\
\text { versus funcionário público }\end{array}$ & \multicolumn{2}{|c|}{ funcionário público (base) } & \multicolumn{2}{|c|}{ assalariado informal (base) } \\
\hline & valor & $\%$ & valor & $\%$ \\
\hline diferencial total & $\begin{array}{l}-2,6361^{\star \star} \\
(1,0337)\end{array}$ & 100,0 & $\begin{array}{l}2,6361^{\star \star} \\
(1,0337)\end{array}$ & 100,0 \\
\hline parcela explicada & $\begin{array}{c}0,0303 \\
(0,0208)\end{array}$ & $-1,1$ & $\begin{array}{c}0,2461 \\
(0,1749)\end{array}$ & 9,3 \\
\hline parcela não explicada & $\begin{array}{l}-2,6664^{\star *} \\
(1,0350)\end{array}$ & 101,1 & $\begin{array}{l}2,3900^{\star \star} \\
(1,2031)\end{array}$ & 90,7 \\
\hline $\begin{array}{l}\text { autônomo informal versus } \\
\text { assalariado/autônomo formal }\end{array}$ & \multicolumn{2}{|c|}{ assalariado/autônomo formal (base) } & \multicolumn{2}{|c|}{ autônomo informal (base) } \\
\hline & valor & $\%$ & valor & $\%$ \\
\hline diferencial total & $\begin{array}{c}0,3125 \\
(0,2982)\end{array}$ & 100,0 & $\begin{array}{l}-0,3125 \\
(0,2982)\end{array}$ & 100,0 \\
\hline parcela explicada & $\begin{array}{c}-0,2154^{\star \star \star} \\
(0,0544)\end{array}$ & $-68,9$ & $\begin{array}{l}0,0581^{* \star *} \\
(0,0220)\end{array}$ & $-18,6$ \\
\hline parcela não explicada & $\begin{array}{c}0,5279 \\
(0,3497) \\
\end{array}$ & 168,9 & $\begin{array}{l}-0,3705 \\
(0,3038)\end{array}$ & 118,6 \\
\hline $\begin{array}{l}\text { autônomo informal } \\
\text { versus funcionário público }\end{array}$ & \multicolumn{2}{|c|}{ funcionário público (base) } & \multicolumn{2}{|c|}{ autônomo informal (base) } \\
\hline & valor & $\%$ & valor & $\%$ \\
\hline diferencial total & $\begin{array}{l}-1,0386 \\
(1,0686)\end{array}$ & 100,0 & $\begin{array}{c}1,0386 \\
(1,0686)\end{array}$ & 100,0 \\
\hline parcela explicada & $\begin{array}{l}-0,1910^{* * *} \\
(0,0330)\end{array}$ & 18,4 & $\begin{array}{c}0,2224 \\
(0,1399)\end{array}$ & 21,4 \\
\hline parcela não explicada & $\begin{array}{l}-0,8475 \\
(1,0728)\end{array}$ & 81,6 & $\begin{array}{c}0,8162 \\
(1,1999)\end{array}$ & 78,6 \\
\hline $\begin{array}{l}\text { assalariado/autônomo formal } \\
\text { versus funcionário público }\end{array}$ & \multicolumn{2}{|c|}{ funcionário público (base) } & \multicolumn{2}{|c|}{ assalariado/autônomo formal (base) } \\
\hline & valor & $\%$ & valor & $\%$ \\
\hline diferencial total & $\begin{array}{l}-1,3510 \\
(1,0312)\end{array}$ & 100,0 & $\begin{array}{c}1,3510 \\
(1,0312)\end{array}$ & 100,0 \\
\hline parcela explicada & $\begin{array}{l}-0,1159^{\star \star *} \\
(0,0274)\end{array}$ & 8,6 & $\begin{array}{l}0,0525 \\
(0,2015)\end{array}$ & 3,9 \\
\hline parcela não explicada & $\begin{array}{l}-1,2352 \\
(1,0324) \\
\end{array}$ & 91,4 & $\begin{array}{c}1,2985 \\
(1,2274) \\
\end{array}$ & 96,1 \\
\hline
\end{tabular}

Fonte: Elaboração própria a partir dos dados do Censo Demográfico de 2000.

Notas: Desvios padrão robustos entre parênteses. ${ }^{* *}$ Estatisticamente significante a $1 \%{ }^{* *}$ Estatisticamente significante a $5 \%$. 
Em geral, as evidências obtidas revelam diferenças salariais desfavoráveis aos migrantes empregados como assalariados informais, independentemente da categoria ocupacional de comparação. Mais especificamente, quando se compara o migrante ocupado como assalariado informal com aquele empregado como assalariado/autônomo formal, percebe-se que há uma vantagem salarial para os últimos em torno de 128,5\%, sendo mais de $90 \%$ desta diferença de salários entre os referidos grupos imputada a fatores não observados. Nas comparações entre migrantes assalariados informais e autônomos informais e entre os primeiros e os funcionários públicos, percebe-se o mesmo padrão de importância dos atributos não observados, apesar da não significância estatística para a parcela do diferencial explicada por atributos observados. Destarte, tais resultados são consistentes com aqueles reportados nas regressões de salários, favoráveis à noção de que os migrantes rural-urbano ocupados como assalariados informais seriam trabalhadores negativamente selecionados em dotações não observadas.

Apesar de a análise de decomposição de Blinder-Oaxaca fornecer evidências acerca da relevância de atributos observados e não observados sobre as diferenças salariais, não permite uma avaliação mais detalhada acerca do impacto da condição de ocupação do migrante sobre a distribuição dos rendimentos. Destarte, no intuito de explorar com maior propriedade a racionalidade econômica envolvida na escolha ocupacional do migrante rural-urbano, apresentam-se, a seguir, os resultados derivados de outro conjunto de exercícios contrafactuais, semelhante ao empregado por Tunali (2000). Nesses exercícios, são utilizados os coeficientes obtidos na regressão do modelo de seleção ocupacional (vide Tabela 2) para predizer os salários-hora (em logaritmo) por categoria de ocupação. As predições lineares fora da amostra, isto é, caso o migrante estivesse em outra ocupação, referem-se aos valores contrafactuais obtidos com a imputação dos coeficientes estimados para uma ocupação alternativa sobre os atributos do migrante observado em uma dada ocupação. Logo, a diferença entre o salário factual (predito dentro da amostra por ocupação observada) e o salário contrafactual, conforme explicitado na Equação (6), fornece o retorno econômico derivado da escolha ocupacional.

No intuito de organizar a exposição dos resultados, nas próximas figuras são apresentadas as distribuições de probabilidade dos salários-hora factuais, contrafactuais e do retorno econômico potencial 
à escolha ocupacional. ${ }^{24}$ Inicialmente, as Figuras $2 \mathrm{a}$ e $2 \mathrm{~b}$ apresentam estimativas das densidades de probabilidade para os salários-hora (estimador kernel com núcleo gaussiano). Vale lembrar que nas referidas figuras o salário-hora factual foi aquele obtido na ocupação escolhida (assalariado informal - Figura 2a e autônomo informal Figura 2 b), enquanto o contrafactual refere-se ao rendimento que seria auferido em caso de mudança para o emprego assalariado/ autônomo formal (contrafactual). Logo, a respectiva diferença dos salários supracitados fornece o retorno econômico potencial, ${ }^{25}$ cuja distribuição percentual é registrada na Figura 2c para os migrantes ocupados como assalariados informais, e na Figura $2 \mathrm{~d}$ para aqueles ocupados como autônomo informais (estimador histograma).
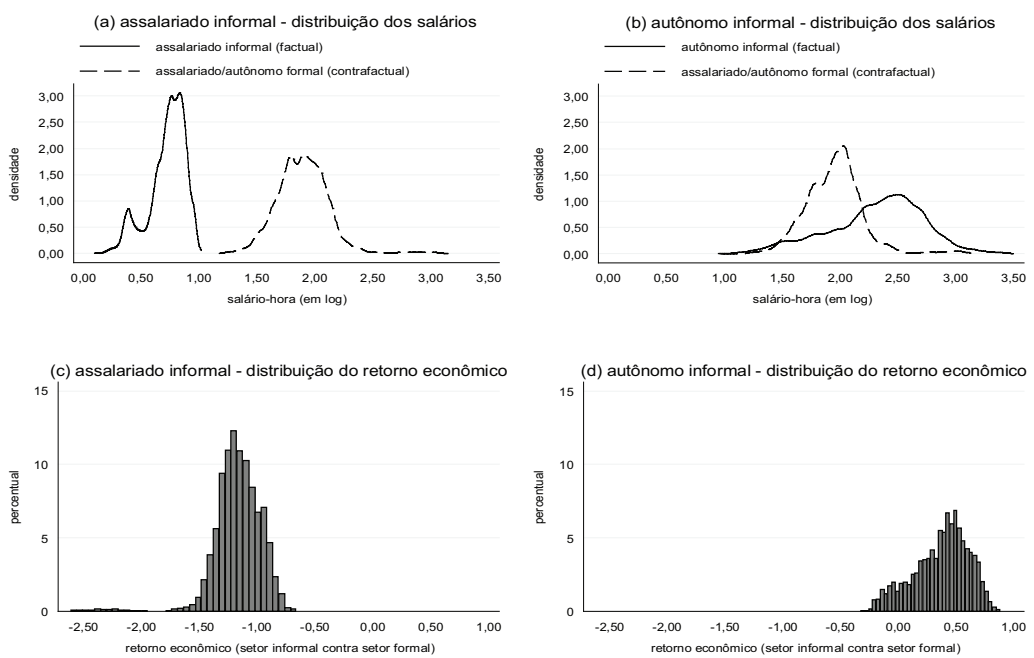

Figura 2 - Migrante rural-urbano - Distribuição dos salários-hora factuais, contrafactuais e do retorno econômico: emprego no setor informal versus transição para o setor formal privado

Fonte: Elaboração própria a partir dos dados do Censo Demográfico de 2000.

Notas: Função de densidade kernel de núcleo gaussiano. Parâmetros de suavização obtidos pelo método plug-in de Silverman (1986).

${ }^{24}$ Conforme já discutido na seção da estratégia empírica, o retorno econômico potencial considera a distribuição incondicional dos rendimentos preditos, isto é, já descontado o impacto da variável de correção para viés de seleção amostral. O mesmo vale para os salários-hora potenciais.

25 A diferença salarial em logaritmo fornece uma aproximação da taxa de retorno à escolha ocupacional, isto é, o retorno econômico. Outra vantagem o uso dos salários-hora em logaritmos é a redução da assimetria (variabilidade) na distribuição estimada (vide Dinardo et al.,1996). 
Os resultados mostram diferenças importantes na distribuição dos rendimentos do trabalho, sobretudo no caso de os migrantes alocados no setor informal transitarem para o setor formal privado. Primeiro, observa-se, a partir da Figura 2a, uma característica bimodal no tocante à distribuição factual dos rendimentos dos migrantes ocupados como assalariados informais, ou seja, verifica-se a presença de dois grupos com médias salariais distintas, sendo que o grupo localizado à esquerda da cauda da referida distribuição registra média de rendimento relativamente inferior. Note-se ainda que estes últimos receberiam maior salário-hora caso ingressassem no setor formal privado, dado que a distribuição contrafactual dos rendimentos situa-se totalmente à direita da distribuição factual. Tal evidência é sintetizada a partir da observação da distribuição percentual do retorno econômico derivada do emprego assalariado informal (Figura 2c), que registra valores negativos em toda distribuição.

Nesse contexto, é importante ressaltar que o ingresso do migrante rural-urbano no emprego assalariado informal, mesmo com retorno econômico negativo, pode não ser resultado da incapacidade de antever ganhos alternativos em outras ocupações, mas estar condicionado à presença de barreiras à entrada nos setores formal privado e informal (trabalho autônomo), seja devido ao maior requerimento de instrução, no primeiro caso, seja de habilidades específicas ou capital físico, no segundo (Banerjee, 1983; Cole e Sanders, 1985).

A partir dos dados da Figura 2 também é possível observar que a distribuição factual dos rendimentos referentes aos migrantes ocupados como autônomos informais (Figura 2b) é unimodal e assimétrica à esquerda (concentradora de probabilidade nessa região), o que indica maior desigualdade de renda entre os migrantes autônomos. Ademais, neste segmento do setor informal, os rendimentos observados (factuais) dos migrantes ocupados como autônomos são, em geral, superiores àqueles registrados para os migrantes assalariados.

Por outro lado, a análise contrafactual permite inferir que, caso os migrantes autônomos estivessem empregados no setor formal, a distribuição contrafactual de salários estaria situada à esquerda da factual (Figura 2b), o que revela rendimentos relativamente menores para a maior parte desses trabalhadores. Os dados da Figura 2d reforçam essa constatação, visto que o retorno econômico resultante da opção pelo trabalho autônomo é positivo para a maioria dos mi- 
grantes ocupados nessa categoria. Destarte, as evidências sugerem que, comparada ao ingresso no setor formal privado, a permanência no emprego autônomo informal parece guardar consistência com hipótese a racionalidade econômica dos migrantes.

Na Figura 3, abaixo, são apresentados os resultados de exercícios contrafactuais similares aos anteriores, no entanto, considerando-se a transição do migrante empregado como assalariado ou autônomo informal para o setor público.
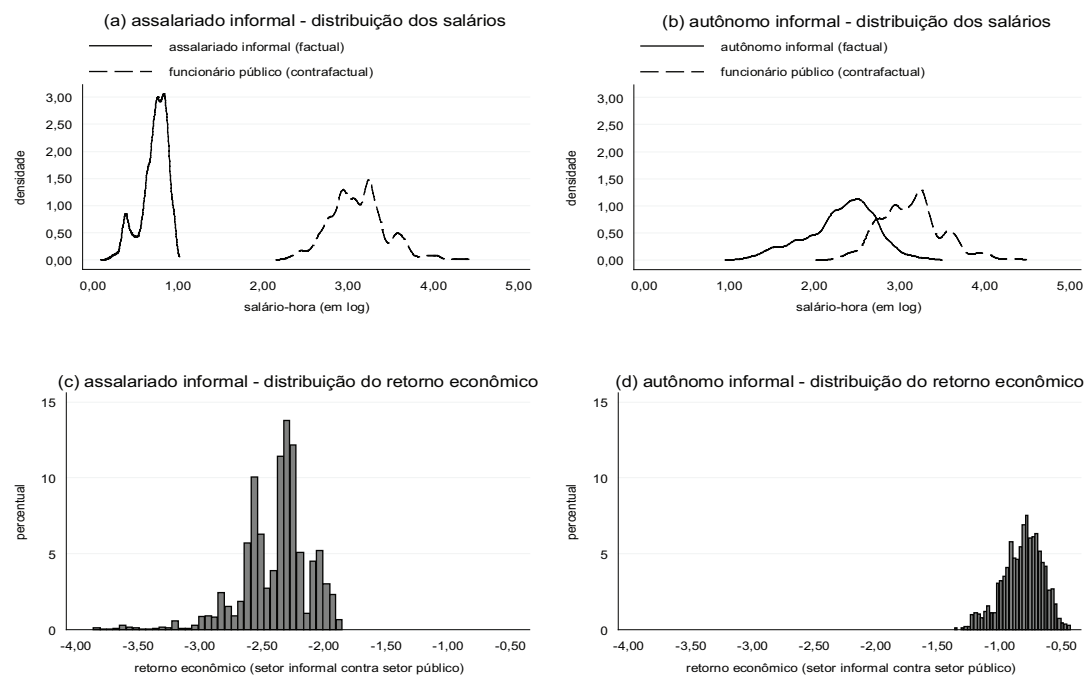

Figura 3 - Migrante rural-urbano - Distribuição dos salários-hora factuais, contrafactuais e do retorno econômico: emprego no setor informal versus transição para o setor público

Fonte: Elaboração própria a partir dos dados do Censo Demográfico de 2000.

Notas: Função de densidade kernel de núcleo gaussiano. Parâmetros de suavização obtidos pelo método plug-in de Silverman (1986).

Os resultados indicam diferenças importantes em relação aos resultados das figuras anteriores. A despeito das distintas ocupações no setor informal, como se apreende a partir dos cotejos entre as distribuições das Figuras 3a e 3b, de forma geral, os migrantes de rota rural-urbana receberiam maior rendimento caso estivessem alocados no setor público, sobretudo aqueles inicialmente empregados como assalariados. De fato, de acordo com as distribuições do retorno eco- 
nômico da inserção entre as categorias consideradas (Figuras 3c 3d), percebe-se que o retorno econômico é sempre negativo para ambas as categorias de ocupações informais, diferentemente do observado no conjunto de evidências anterior. Tais evidências são consistentes com a hipótese de barreiras à entrada no setor público, geralmente condicionadas pelo elevado nível de instrução formal deste segmento, além de exames para admissão.

\section{Conclusão}

Este trabalho analisou a importância do setor informal no processo de migração rural-urbana no Brasil no período 1995-2000, país continental em desenvolvimento que, de forma singular apresenta, por um lado, quase metade das ocupações no setor informal (aproximando-se da China e Índia) e, por outro lado, relativamente baixa presença da população no meio rural (aproximando-se dos Estados Unidos). Especificamente, primeiro, procurou-se fornecer evidências a respeito do papel do capital humano do migrante para a sua inserção entre as ocupações informal e formal do mercado de trabalho urbano.

A seguir, investigou-se se o setor informal brasileiro representa apenas um campo transitório para o migrante rural-urbano que, posteriormente, passaria a ocupar postos formais. Finalmente, analisou-se em que medida a inserção observada do migrante representa a escolha de maior rendimento esperado, dadas suas dotações com respeito a características produtivas. Até o presente, questões que não foram conjuntamente tratadas na literatura econômica sobre o país.

A partir da consideração de categorias alternativas para inserção no mercado de trabalho (assalariado/autônomo informal, assalariado informal, autônomo informal e funcionário público), verificou-se que as dotações de capital humano tiveram um papel decisivo para a qualidade da alocação inicial do migrante nos diferentes segmentos do mercado de trabalho das cidades. De forma geral, migrantes mais escolarizados apresentaram maiores chances de alocação nos segmentos formais, principalmente no setor público, o que indica que, em características observáveis, os migrantes inseridos nos segmentos formais são positivamente selecionados. Por sua vez, a partir da estimação de parâmetros de equações de salários corrigidas para viés de seleção amostral e da decomposição salarial, foi possível observar 
que os migrantes ocupados como autônomos informais seriam positivamente selecionados em atributos produtivos não observáveis, enquanto os assalariados informais seriam negativamente selecionados.

Com respeito à funcionalidade do setor informal brasileiro como campo transitório para os segmentos formais (Cole e Sanders, 1985), observou-se que o tempo de permanência na cidade de destino parece elevar consideravelmente as chances de inserção do migrante recém-chegado no setor formal privado, ao passo que desfavorece a permanência no segmento informal assalariado. Além disto, tal processo tende a ser mais acelerado para os migrantes com o aumento da instrução. Ou seja, os níveis de capital humano do migrante oriundo do meio rural são não apenas decisivos para sua inserção inicial, como também parecem fundamentais para as chances de realocação no mercado de trabalho urbano. O setor informal urbano, assim, parece favorecer a migração rural-urbana mesmo quando as chances de emprego nos segmentos formais são bastante reduzidas.

Particularmente, no que tange à ocupação informal autônoma depois de considerar as influências de várias características individuais, constatou-se que a probabilidade de absorção do migrante rural-urbano nesse setor não reage ao aumento do tempo de residência na cidade, isto é, o migrante que entra no setor informal autônomo tende a permanecer nesse tipo de trabalho por considerável parte de tempo. Tais evidências guardam consonância com aquelas encontradas por Meng (2001) ao estudar a relação entre migração rural-urbana e setor informal na China, assim como respaldam a hipótese de Banerjee (1983), que atribui ao trabalho autônomo a exigência de habilidades mais especificas que aquelas demandas pelo trabalho assalariado.

Por fim, as evidências sobre o retorno esperado dos migrantes nas diferentes categorias do mercado de trabalho brasileiro sugerem que estas são consistentes com a escolha racional das ocupações por parte dos migrantes, uma vez que, ao longo do tempo, os migrantes tendem a deixar ocupações informais de menor remuneração e inserirem-se em ocupações formais de maior remuneração, e com a existência de barreiras de capital humano à entrada nas ocupações do setor público e de barreiras referentes a habilidades específicas e/ou dotações associadas ao capital físico para o trabalho autônomo informal. 


\section{Referências}

AGESA, R.U. Migration and the Urban to Rural Earnings Difference: A Sample Selection Approach. Economic Development and Cultural Change, v. 49, n. 4, p. 847-865, 2001.

JANN, BEN . The Blinder-Oaxaca decomposition for linear regression models. The Stata Journal, v.8, n.4, p.453-479, 2008.

BANERJEE, B. The Role of the Informal Sector in the Migration Process: A Test of Probabilistic Migration Models and Labor Market Segmentation for India. Oxford Economic Papers, v. 35, n. 3, p. 399-422, 1983.

CACCIAMALI, M.C.; FERNANDES, R. Distribuição dos trabalhadores e diferenciais de salários entre mercados de trabalho regulamentado e não regulamentado, Pesquisa e Planejamento Econômico, v. 23, n. 1, 1993, p.135-156.

CAMERON, A.C. ; TRIVEDI, P.K. Microeconometrics: Methods and Applications. Cambridge University Press, 2005.

COLE, W.E; SANDERS, R.D. Internal Migration and Urban Employment in the Third World. American Economic Review, v. 75, n. 3, p. 481-494, 1985.

CURI, A.Z.; MENEZES-FILHO, N.A. Os Determinantes das Transições Ocupacionais no Mercado de trabalho brasileiro. Anais do XXXII Encontro Nacional da Anpec, 2004.

DAHL, G.B. Mobility and the Return to Education: Testing a Roy Model with Multiple Markets. Econometrica, v. 70, n. 6, p. 2367-2420, 2002.

DIMOVA, R.; NORDMAN,C.J.;ROUBAUD,F. Allocation of Labour in Urban West Africa: Implication for Development Policies. IZA Discussion Paper $n^{\circ}$ 3558, p.1-35, 2008.

DINARDO, J.; FORTIN, N. M.; LEMIEUX, T. Labor market institutions and the distribution of wages, 1973-1992: A Semiparametric Approach. Econometrica, v. 64, n. 5, p. 1001-1044, 1996.

DOLTON, P.J.; MAKEPEACE,G.H.; KLAAU, Van der. Occupational Choice and Earnings Determination: The Role of Sample Selection and Non-Pecuniary Factors. Oxford Economic Papers, v. 41, n. 3, p. 573-594, 1989.

FIESS, N.M.; VERNER, D. Migration and human capital in Brazil during 1990s. World Bank Policy Research Working Paper, n. 3093, p. 1-39, 2003.

GREENE, W.H. Econometrics Analysis. Prentice Hall; 5 ed., 2002.

HECKMAN, J. Sample selection bias as a specification error. Econometrica. v. 47, p. 153-161, 1979.

IBGE. Pesquisa Nacional por Amostra de Domicílios 2008. Rio de Janeiro: IBGE, 2009. 1 CD-ROM.

LALL, S.L.; SELOD, H.; SHALIZI, Z. Rural-Urban migration in developing countries: a survey of theoretical predictions and empirical findings. World Bank Policy Research Working Paper $n^{o}$ 3915, p.1-63, 2006.

.Censo Demográfico de 2000. Rio de Janeiro: IBGE, 2002. CD-ROM.

.Censo Demográfico de 1991. Rio de Janeiro: IBGE, 1996. CD-ROM.

LEE, Lung-Fei. Generalized Econometric Models with Selectivity. Econometrica, v. 51, n. 2, p. 507$512,1983$.

LOKSHIN, M., SAJAIA, Z. Maximum likelihood estimation of endogenous switching regression models. The Stata Journal, v.4, n. 3, 2004.

MADDALA, G. Limited-dependent and qualitative variables in Econometrics. Cambridge : Cambridge University Press, 1983.

MENG, X. The Informal Sector and Rural-Urban Migration - A Chinese Case Study. Asian Economic Journal, v.15, n.1, p.71-89, 2001.

NELSON, F.D. Efficiency of the Two-Step Estimator for Models with Endogenous Sample Selection. Journal of Econometrics, v.24, p.181-196, 1984.

Est. Econ., São Paulo, vol. 42, n.4, p. 731-771, out.-dez. 2012 
NERI, M.C. Decent Work and the Informal Sector in Brazil. EPGE, Ensaios Econômicos, n. 461, 2002.

OAXACA, R.L; RANSOM, M.R. Identification in Detailed Wage Decompositions. The Review of Economics and Statistics, v. 81, n. 1, p. 154-157.

OECD. Working Party on Employment : Labour Markets In The Brics (Brazil, The Russian Federation, India And China).In: Directorate for Employment, Labour and Social Affairs, 2007,p.1-35. Disponível em: <http://www.oecd.org/dataoecd/54/23/38355687.pdf>. Acesso em: 15 de dez.2009.

PIRACHA, M.;VADEAN, F. Return migration and occupational choice. IZA Working Papers, n. 3.922, 2009, p.1-34.

PUHANI, P.A. The Heckman correction for sample selection and its critique. Journal of economic surveys. v. 14, n. 1, 2000.

RAMOS, L. A evolução da informalidade no Brasil metropolitano: 1991-2001. IPEA, texto para discussão n. 914, 2002.

RIADH, B.J.; HASSEN, M. Rural-urban migration and self-selection in Tunísia. Papers in Regional Science, v.77, n.4, p.347-360, 1998.

SABOIA, J. ; SABOIA, Ana Lucia . Caracterização do Setor Informal a partir dos Dados do Censo Demográfico do Brasil de 2000. In: Política Geral de Emprego: Necessidades, Opções, Prioridades, 2004, Brasilia. Trabalho Docente. Brasilia : OIT, 2004. v. 1., p.1-32.Disponível em: < http://www. redcelsofurtado.edu.mx/archivosPDF/saboia2.pdf>. Acesso em: 30 de set. 2008.

SANTOS JÚNIOR, E. R.; MENEZES-FILHO, N; FERREIRA, P.C. Migração, seleção e diferenças regionais de renda no Brasil. Pesquisa e Planejamento Econômico, v.35, n.3, p. 299-331, 2005.

SILVERMAN, B. Density estimation for statistics and data analysis. London: Chapman \& Hall, 1986.

SOARES, F.V. Some Stylized Facts of the Informal Sector in Brazil. IPEA, texto para discussão, $n$. 1020, 2004.

TUNALI, I. Rationality of migration. International Economic Review. v.41, n.4, p.893-920, 2000.

TANNURI-PIANTO, M.E.; PIANTO, D. "Informal Employment in Brazil - A Choice at the Top and Segmentation at the Bottom: A Quantile Regression Approach”. Anais do XXIV Encontro Brasileiro de Econometria, v. 2, 2002.

ULYSSEA, Gabriel. Informalidade no mercado de trabalho brasileiro: uma resenha da literatura. Revista de Economia Politica, v.26, n.4, São Paulo, 2006.

UNITED NATIONS. World Urbanization Prospects: The 2007 Revision Population Database, 2007. Disponível em: $<$ http://esa.un.org/unup/index.asp> Acesso em: 30 nov. 2007.

VIJVERBERG, W.P.M. Dual Selection Criteria with Multiple Alternatives: Migration, Work Status, and Wages. International Economic Review, v. 36, n. 1, p. 159-185, 1995.

YAP, Lorene Y.L. Rural-urban migration and urban underemployment in Brazil. Journal of Development Economics,v.3, n.3, p.227-243, 1976. 


\section{Apêndice}

Quadro Al - Descrição das variáveis utilizadas nos modelos

\begin{tabular}{|c|c|c|}
\hline Variável & Descrição & $\begin{array}{l}\text { Variáveis originais do Censo } \\
\text { Demográfico de } 2000\end{array}$ \\
\hline Homem & Dummy: 1 se homem; 0 se mulher*. & V0401 \\
\hline Branco & Dummy: 1 se declara cor de pele branca; 0 caso contrário*. & V0408 \\
\hline Idade & Idade em anos. & V4752 \\
\hline Idade2 & Idade ao quadrado. & V4752 \\
\hline Tempo na cidade & Tempo de residência no município (até anos). & V0416 \\
\hline Educação 1 a 4 & $\begin{array}{l}\text { Dummy: } 1 \text { se tem de } 1 \text { a } 4 \text { anos completos de escolaridade; } 0 \\
\text { menos de } 1 \text { ano de estudo*. }\end{array}$ & V4300 \\
\hline Educação 5 a 8 & $\begin{array}{l}\text { Dummy: } 1 \text { se tem de } 5 \text { a } 10 \text { anos completos de escolaridade; } 0 \\
\text { menos de } 1 \text { ano de estudo*. }\end{array}$ & V4300 \\
\hline Educação 9 a 11 & $\begin{array}{l}\text { Dummy: } 1 \text { se tem de } 9 \text { a } 11 \text { anos completos de escolaridade; } 0 \\
\text { menos de } 1 \text { ano de estudo*. }\end{array}$ & V4300 \\
\hline Educação 12 ou mais & $\begin{array}{l}\text { Dummy: } 1 \text { se tem de } 12 \text { anos ou mais completos de escolarida- } \\
\text { de; } 0 \text { menos de } 1 \text { ano de estudo *. }\end{array}$ & V4300 \\
\hline Chefe & Dummy: 1 se é o responsável pelo domicílio; 0 caso contrário*. & V0402 \\
\hline Casado & Dummy: 1 se vive com cônjuge; 0 caso contrário*. & V0436 \\
\hline Moradores no domicílio & Número de moradores no domicílio. & V7100 \\
\hline Migrantes no domicílio & $\begin{array}{l}\text { Número de migrantes interestaduais no domicílio com mais de } \\
5 \text { anos de residência no estado. }\end{array}$ & V4230,V0416,V0300,V0102 \\
\hline Trabalhadores no domicílio & Número de pessoas com trabalho remunerado no domicílio. & V0102, V0300, V0439 \\
\hline Norte (destino) & $\begin{array}{l}\text { Dummy: } 1 \text { se reside na região Norte; } 0 \text { se reside na região } \\
\text { Sudeste }^{\star} \text {. }\end{array}$ & V1001 \\
\hline Nordeste (destino) & $\begin{array}{l}\text { Dummy: } 1 \text { se reside na região Nordeste; } 0 \text { se reside na região } \\
\text { Sudeste *. }\end{array}$ & V1001 \\
\hline Sul (destino) & $\begin{array}{l}\text { Dummy: } 1 \text { se reside na região Sul; } 0 \text { se reside na região } \\
\text { Sudeste *. }\end{array}$ & V1001 \\
\hline Centro-Oeste ( destino) & $\begin{array}{l}\text { Dummy: } 1 \text { se reside na região Centro-Oeste; } 0 \text { se reside na } \\
\text { região Sudeste *. }\end{array}$ & V1001 \\
\hline Norte (origem) & $\begin{array}{l}\text { Dummy: } 1 \text { se há cinco anos morava na região Norte; } 0 \text { se há } \\
\text { cinco anos morava na região Nordeste*. }\end{array}$ & V4260 \\
\hline Sudeste (origem) & $\begin{array}{l}\text { Dummy: } 1 \text { se há cinco anos morava na região Sudeste; } 0 \text { se há } \\
\text { cinco anos morava na região Nordeste *. }\end{array}$ & V4260 \\
\hline Sul (origem) & $\begin{array}{l}\text { Dummy: } 1 \text { se há cinco anos morava na região Sul; } 0 \text { se há } \\
\text { cinco anos morava na região Nordeste *. }\end{array}$ & V4260 \\
\hline Centro-Oeste (origem) & $\begin{array}{l}\text { Dummy: } 1 \text { se há cinco anos morava na região Centro-Oeste; } 0 \\
\text { se há cinco anos morava na região Nordeste *. }\end{array}$ & V4260 \\
\hline Salário-hora & $\begin{array}{l}\text { Rendimento do trabalho principal por horas trabalhadas durante } \\
\text { a semana }\end{array}$ & V4513, V0453 \\
\hline ocupação & $\begin{array}{l}\text { 1- se assalariado/autônomo formal; } 2 \text { - se assalariado informal; } \\
3 \text { - autônomo informal e } 4 \text { - se funcionário público }\end{array}$ & V0447, V0450, V0448 \\
\hline
\end{tabular}

Fonte: Elaboração própria a partir dos dados do Censo Demográfico de 2000. Nota: * Categoria de referência (omitida). No caso das regiões, foi considerada a maior frequência amostral. 
Tabela Al - Brasil: Determinantes da escolha ocupacional do migrante ruralurbano - modelo multinomial na forma reduzida - coeficientes

\begin{tabular}{|c|c|c|c|}
\hline & Assalariado informal & Autônomo informal & Funcionário público \\
\hline homem & $\begin{array}{c}-0,6613^{\star \star *} \\
(0,0392)\end{array}$ & $\begin{array}{c}0,2209^{* * *} \\
(0,0560)\end{array}$ & $\begin{array}{c}-0,4888^{* \star \star} \\
(0,1317)\end{array}$ \\
\hline branco & $\begin{array}{c}-0,1745^{\star \star \star} \\
(0,0322)\end{array}$ & $\begin{array}{c}0,0072 \\
(0,0396)\end{array}$ & $\begin{array}{l}-0,1378 \\
(0,1050)\end{array}$ \\
\hline idade & $\begin{array}{l}-0,0152 \\
(0,0094)\end{array}$ & $\begin{array}{c}0,0767^{\star \star \star} \\
(0,0113)\end{array}$ & $\begin{array}{c}0,1168^{\star \star \star} \\
(0,0306)\end{array}$ \\
\hline idade2 & $\begin{array}{l}0,0004^{\star \star \star} \\
(0,0001)\end{array}$ & $\begin{array}{c}-0,0004^{\star \star *} \\
(0,0001)\end{array}$ & $\begin{array}{c}-0,0011^{\star \star \star} \\
(0,0004)\end{array}$ \\
\hline educação de 1 a 4 & $\begin{array}{c}-0,2921^{\star \star *} \\
(0,0445)\end{array}$ & $\begin{array}{r}-0,0309 \\
(0,0543)\end{array}$ & $\begin{array}{l}-0,1869 \\
(0,1683)\end{array}$ \\
\hline educação de 5 a 8 & $\begin{array}{c}-0,5078^{\star \star *} \\
(0,0518)\end{array}$ & $\begin{array}{l}-0,0186 \\
(0,0642)\end{array}$ & $\begin{array}{c}0,1005 \\
(0,1889)\end{array}$ \\
\hline educação de 9 a 11 & $\begin{array}{c}-1,2076^{\star \star \star} \\
(0,0695)\end{array}$ & $\begin{array}{c}-0,3903^{\star \star \star} \\
(0,0842)\end{array}$ & $\begin{array}{c}1,0319^{\star \star \star} \\
(0,1854)\end{array}$ \\
\hline educação 12 ou mais & $\begin{array}{c}-1,1157^{\star \star \star} \\
(0,1256)\end{array}$ & $\begin{array}{c}-0,4253^{\star \star *} \\
(0,1395)\end{array}$ & $\begin{array}{l}1,9506^{\star \star *} \\
(0,2023)\end{array}$ \\
\hline Norte (destino) & $\begin{array}{l}0,8734^{\star \star \star} \\
(0,0670)\end{array}$ & $\begin{array}{l}1,2847^{\star \star \star} \\
(0,0768)\end{array}$ & $\begin{array}{l}1,8569^{* * *} \\
(0,1877)\end{array}$ \\
\hline Nordeste (destino) & $\begin{array}{l}1,0939^{\star \star \star} \\
(0,0625)\end{array}$ & $\begin{array}{c}1,6701^{\star \star \star} \\
(0,0706)\end{array}$ & $\begin{array}{c}1,7056^{\star \star \star} \\
(0,1959)\end{array}$ \\
\hline Sul (destino) & $\begin{array}{l}-0,0469 \\
(0,0686)\end{array}$ & $\begin{array}{c}0,0242 \\
(0,0833)\end{array}$ & $\begin{array}{l}-0,1608 \\
(0,2181)\end{array}$ \\
\hline Centro-Oeste (destino) & $\begin{array}{l}0,4308^{\star * *} \\
(0,0493)\end{array}$ & $\begin{array}{l}0,4166^{\star * *} \\
(0,0645)\end{array}$ & $\begin{array}{l}0,8940^{* * *} \\
(0,1632)\end{array}$ \\
\hline Norte (origem) & $\begin{array}{l}0,2502^{\star \star \star} \\
(0,0710)\end{array}$ & $\begin{array}{c}0,4169^{* * *} \\
(0,0791)\end{array}$ & $\begin{array}{c}0,7020^{\star \star \star} \\
(0,1874)\end{array}$ \\
\hline Sudeste (origem) & $\begin{array}{l}0,1964^{\star \star \star} \\
(0,0431)\end{array}$ & $\begin{array}{c}0,2065^{\star \star *} \\
(0,0574)\end{array}$ & $\begin{array}{l}0,7350^{\star \star *} \\
(0,1604)\end{array}$ \\
\hline Sul (origem) & $\begin{array}{c}0,0441 \\
(0,0642)\end{array}$ & $\begin{array}{c}0,1206 \\
(0,0793)\end{array}$ & $\begin{array}{l}0,4093^{\star *} \\
(0,1953)\end{array}$ \\
\hline Centro-Oeste (origem) & $\begin{array}{c}0,3563^{\star \star *} \\
(0,0611)\end{array}$ & $\begin{array}{c}0,4519^{\star * \star} \\
(0,0751)\end{array}$ & $\begin{array}{c}0,6602^{\star \star \star} \\
(0,1847)\end{array}$ \\
\hline chefe & $\begin{array}{c}-0,2676^{\star \star \star} \\
(0,0408)\end{array}$ & $\begin{array}{c}-0,1844^{\star \star *} \\
(0,0542)\end{array}$ & $\begin{array}{l}-0,1100 \\
(0,1370)\end{array}$ \\
\hline casado & $\begin{array}{c}-0,1638^{* \star *} \\
(0,0362)\end{array}$ & $\begin{array}{l}0,1048^{\star \star} \\
(0,0492)\end{array}$ & $\begin{array}{c}0,1385 \\
(0,1184)\end{array}$ \\
\hline moradores no domicílio & $\begin{array}{l}0,0506^{\star \star *} \\
(0,0085)\end{array}$ & $\begin{array}{c}0,0314^{\star \star \star} \\
(0,0105)\end{array}$ & $\begin{array}{l}0,0475^{\star} \\
(0,0274)\end{array}$ \\
\hline trabalhadores no domicílio & $\begin{array}{c}-0,0856^{\star \star \star} \\
(0,0139)\end{array}$ & $\begin{array}{c}-0,1365^{\star \star \star} \\
(0,0192)\end{array}$ & $\begin{array}{c}-0,1681^{\star \star \star} \\
(0,0599)\end{array}$ \\
\hline migrantes no domicílio & $\begin{array}{l}-0,0702^{\star} \\
(0,0361)\end{array}$ & $\begin{array}{l}-0,0011 \\
(0,0526)\end{array}$ & $\begin{array}{l}-0,0665 \\
(0,1354)\end{array}$ \\
\hline intercepto & $\begin{array}{l}0,4282^{\star *} \\
(0,1713)\end{array}$ & $\begin{array}{c}-3,5712^{\star \star \star} \\
(0,2156)\end{array}$ & $\begin{array}{c}-6,5260^{\star \star \star} \\
(0,5898)\end{array}$ \\
\hline $\begin{array}{l}\text { Pseudo R2 } \\
\text { Número de observações }\end{array}$ & $\begin{array}{l}0,0827 \\
24.489\end{array}$ & & \\
\hline
\end{tabular}

Fonte: Elaboração própria a partir dos dados do Censo Demográfico de 2000.

Notas: Categoria de referência: setor formal privado. Desvios padrão robustos entre parênteses. ${ }^{* * *}$ Estatisticamente significante a $1 \% .{ }^{* *}$ Estatisticamente significante a $5 \% .{ }^{*}$ Estatisticamente significante a $10 \%$. 
Tabela A2 - Estatísticas descritivas da amostra por condição de ocupação e tempo de residência na cidade-migrantes rural-urbano (1995-2000)

\begin{tabular}{|c|c|c|c|c|c|c|c|c|}
\hline \multirow[b]{2}{*}{ Variável } & \multicolumn{2}{|c|}{$\begin{array}{c}\text { Assalariado/ } \\
\text { autônomo formal }\end{array}$} & \multicolumn{2}{|c|}{$\begin{array}{c}\text { Assalariado } \\
\text { informal }\end{array}$} & \multicolumn{2}{|c|}{$\begin{array}{c}\text { Autônomo } \\
\text { informal }\end{array}$} & \multicolumn{2}{|c|}{$\begin{array}{c}\text { Funcionário } \\
\text { público }\end{array}$} \\
\hline & $\begin{array}{l}\text { Até } 1 \\
\text { ano }\end{array}$ & $\begin{array}{l}\text { De } 3 \text { a } \\
4 \text { anos }\end{array}$ & $\begin{array}{l}\text { Até } 1 \\
\text { ano }\end{array}$ & $\begin{array}{l}\text { De } 3 \text { a } \\
4 \text { anos }\end{array}$ & $\begin{array}{l}\text { Até } \\
1 \text { ano }\end{array}$ & $\begin{array}{l}\text { De } 3 \text { a } \\
4 \text { anos }\end{array}$ & $\begin{array}{l}\text { Até } \\
1 \text { ano }\end{array}$ & $\begin{array}{l}\text { De } 3 \text { a } \\
4 \text { anos }\end{array}$ \\
\hline \multicolumn{9}{|l|}{ Gênero* } \\
\hline mulher & $22,4 \%$ & $26,0 \%$ & $36,0 \%$ & $38,9 \%$ & $17,9 \%$ & $18,4 \%$ & $33,1 \%$ & $36,7 \%$ \\
\hline homem & $77,6 \%$ & $74,0 \%$ & $64,0 \%$ & $61,1 \%$ & $82,1 \%$ & $81,6 \%$ & $66,9 \%$ & $63,3 \%$ \\
\hline \multicolumn{9}{|l|}{ Raça* } \\
\hline não branco & $44,9 \%$ & $47,8 \%$ & $56,9 \%$ & $55,0 \%$ & $52,7 \%$ & $52,1 \%$ & $49,1 \%$ & $56,5 \%$ \\
\hline branco & $55,1 \%$ & $52,2 \%$ & $43,1 \%$ & $45,0 \%$ & $47,3 \%$ & $47,9 \%$ & $50,9 \%$ & $43,5 \%$ \\
\hline \multicolumn{9}{|l|}{ Experiência } \\
\hline Idade (média) & 30,9 & 30,2 & 32,3 & 32,6 & 37,1 & 35,7 & 34,0 & 34,5 \\
\hline idade2 (média) & $1.052,5$ & 999,4 & $1.165,5$ & $1.181,0$ & $1.512,4$ & $1.401,3$ & $1.267,4$ & $1.280,9$ \\
\hline \multicolumn{9}{|l|}{ Educação* } \\
\hline menos de 1 ano & $12,6 \%$ & $12,0 \%$ & $19,0 \%$ & $20,8 \%$ & $19,6 \%$ & $18,5 \%$ & $9,2 \%$ & $15,9 \%$ \\
\hline de 1 a 4 anos & $44,0 \%$ & $46,6 \%$ & $48,2 \%$ & $51,3 \%$ & $47,6 \%$ & $52,1 \%$ & $25,2 \%$ & $30,9 \%$ \\
\hline de 5 a 8 anos & $25,7 \%$ & $26,6 \%$ & $24,5 \%$ & $20,8 \%$ & $22,5 \%$ & $21,3 \%$ & $17,8 \%$ & $19,8 \%$ \\
\hline de 9 a 11 anos & $14,6 \%$ & $12,7 \%$ & $6,9 \%$ & $5,8 \%$ & $7,9 \%$ & $6,5 \%$ & $29,4 \%$ & $19,8 \%$ \\
\hline 12 ou mais & $3,1 \%$ & $2,1 \%$ & $1,4 \%$ & $1,3 \%$ & $2,4 \%$ & $1,6 \%$ & $18,4 \%$ & $13,5 \%$ \\
\hline \multicolumn{9}{|l|}{ Condição no domicílio* } \\
\hline não chefe & $45,8 \%$ & $36,9 \%$ & $53,6 \%$ & $44,9 \%$ & $34,5 \%$ & $27,7 \%$ & $44,2 \%$ & $32,4 \%$ \\
\hline chefe & $54,2 \%$ & $63,1 \%$ & $46,4 \%$ & $55,1 \%$ & $65,5 \%$ & $72,3 \%$ & $55,8 \%$ & $67,6 \%$ \\
\hline \multicolumn{9}{|l|}{ Estrutura do domicílio } \\
\hline moradores no domicílio (média) & 4,4 & 4,2 & 4,7 & 4,6 & 4,6 & 4,5 & 4,3 & 4,3 \\
\hline trabalhadores no domicílio (média) & 2,3 & 2,0 & 2,2 & 2,1 & 1,9 & 1,9 & 1,9 & 1,8 \\
\hline migrantes no domicílio (média) & 0,1 & 0,1 & 0,1 & 0,1 & 0,1 & 0,1 & 0,1 & 0,0 \\
\hline \multicolumn{9}{|l|}{ Situação conjugal* } \\
\hline não vive com cônjuge & $38,1 \%$ & $26,6 \%$ & $38,3 \%$ & $27,0 \%$ & $25,3 \%$ & $19,0 \%$ & $31,9 \%$ & $21,7 \%$ \\
\hline vive com cônjuge & $61,9 \%$ & $73,4 \%$ & $61,7 \%$ & $73,0 \%$ & $74,7 \%$ & $81,0 \%$ & $68,1 \%$ & $78,3 \%$ \\
\hline \multicolumn{9}{|l|}{ Rendimento do trabalho } \\
\hline salário-hora (média) & 9,1 & 8,8 & 5,6 & 6,3 & 10,7 & 10,2 & 16,1 & 12,6 \\
\hline \multicolumn{9}{|l|}{ Residência em 2000* } \\
\hline Norte & $7,6 \%$ & $7,9 \%$ & $15,5 \%$ & $14,8 \%$ & $22,1 \%$ & $22,4 \%$ & $26,4 \%$ & $32,9 \%$ \\
\hline Nordeste & $5,6 \%$ & $4,2 \%$ & $11,9 \%$ & $10,1 \%$ & $17,7 \%$ & $14,7 \%$ & $11,7 \%$ & $12,6 \%$ \\
\hline Sudeste & $53,3 \%$ & $58,1 \%$ & $41,9 \%$ & $44,7 \%$ & $28,8 \%$ & $35,7 \%$ & $33,1 \%$ & $24,6 \%$ \\
\hline Sul & $16,9 \%$ & $15,4 \%$ & $10,2 \%$ & $11,2 \%$ & $12,5 \%$ & $10,0 \%$ & $6,1 \%$ & $7,7 \%$ \\
\hline Centro-Oeste & $16,7 \%$ & $14,4 \%$ & $20,5 \%$ & $19,2 \%$ & $18,9 \%$ & $17,2 \%$ & $22,7 \%$ & $22,2 \%$ \\
\hline \multicolumn{9}{|l|}{ Residência em 1995* } \\
\hline Norte & $6,4 \%$ & $6,9 \%$ & $13,0 \%$ & $11,9 \%$ & $17,8 \%$ & $18,4 \%$ & $17,2 \%$ & $27,5 \%$ \\
\hline Nordeste & $40,3 \%$ & $41,3 \%$ & $39,9 \%$ & $41,1 \%$ & $35,4 \%$ & $36,8 \%$ & $25,8 \%$ & $31,4 \%$ \\
\hline Sudeste & $22,3 \%$ & $22,6 \%$ & $21,5 \%$ & $19,5 \%$ & $17,9 \%$ & $17,6 \%$ & $28,8 \%$ & $16,9 \%$ \\
\hline Sul & $22,1 \%$ & $20,7 \%$ & $13,2 \%$ & $15,4 \%$ & $15,4 \%$ & $14,2 \%$ & $11,0 \%$ & $11,6 \%$ \\
\hline Centro-Oeste & $8,9 \%$ & $8,4 \%$ & $12,4 \%$ & $12,1 \%$ & $13,6 \%$ & $13,1 \%$ & $17,2 \%$ & $12,6 \%$ \\
\hline Observações & $\begin{array}{c}4.038 \\
(44,9 \%)\end{array}$ & $\begin{array}{c}5.340 \\
(51,4 \%)\end{array}$ & $\begin{array}{c}3.218 \\
(35,8 \%)\end{array}$ & $\begin{array}{c}3.020 \\
(29,1 \%)\end{array}$ & $\begin{array}{c}1.579 \\
(17,5 \%)\end{array}$ & $\begin{array}{c}1.825 \\
(17,6 \%)\end{array}$ & $\begin{array}{c}163 \\
(1,8 \%)\end{array}$ & $\begin{array}{c}207 \\
(2,0 \%)\end{array}$ \\
\hline
\end{tabular}

Fonte: Elaboração própria a partir dos dados do Censo Demográfico de 2000.

Nota: * Variável qualitativa. 


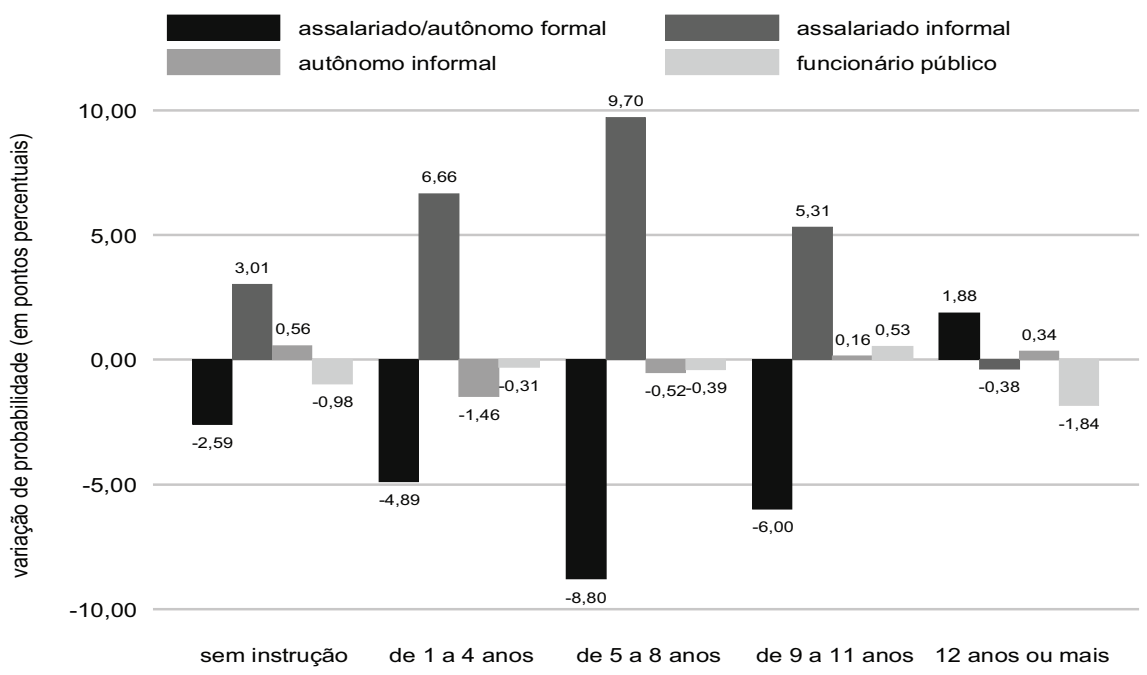

Figura Al - Diferencial de probabilidade contrafactual/factual de emprego segundo categorias de ocupação e por faixas de escolaridademigrantes rural-urbano com 3 ou 4 anos de residência na cidade

Fonte: Elaboração própria a partir dos dados do Censo Demográfico de 2000.

Nota: Contrafactual - em caso de permanência de até 1 ano na cidade. 